\title{
Large breathing effect induced by water sorption in the exceptionally stable nonporous non-MOF crystalline material
}

\author{
Michał Magott, ${ }^{\mathrm{a}, *}$ Bartłomiej Gaweł, ${ }^{\mathrm{b}}$ Marcin Sarewicz, ${ }^{\mathrm{c}}$ Mateusz Reczyński, ${ }^{\mathrm{a}}$ Karolina Ogorzały, ${ }^{\mathrm{a}}$ Wa- \\ cław Makowski, ${ }^{\text {a }}$ Dawid Pinkowicz ${ }^{\mathrm{a}, *}$ \\ ${ }^{a}$ Faculty of Chemistry, Jagiellonian University, Gronostajowa 2, 30-387 Kraków, Poland \\ ${ }^{b}$ Department of Materials Science and Engineering, Norwegian University of Science and Technology (NTNU), 7491 Trond- \\ heim, Norway
}

${ }^{c}$ Department of Molecular Biophysics, Faculty of Biochemistry, Biophysics and Biotechnology, Jagiellonian University, Gronostajowa 7, 30-387 Kraków, Poland

\begin{abstract}
Metal-organic frameworks (MOFs), a class of crystalline coordination polymers (CPs) where long organic linkers (e.g. terephthalate) connect metal centers into 2-D or 3-D coordination frameworks, hold the key to various sorption applications due to their intrinsic porosity. Herein we demonstrate that extraordinary sorption properties can also be observed in non-MOF materials based on extremely short linkers with no porosity whatsoever. A bimetallic nonporous cyanide-bridged coordination polymer $\left\{[\mathrm{Mn}(\mathrm{imH})]_{2}\left[\mathrm{Mo}(\mathrm{CN})_{8}\right]\right\}_{\mathrm{n}}(\mathrm{imH}=$ imidazole $)$ - a distant relative of the famous Prussian Blue - can efficiently and reversibly capture water molecules $>25 \% \mathrm{w} / \mathrm{w}$ over tens of sorption/desorption cycles without any fatigue despite being based on one of the shortest bridging ligands known - the cyanide. The sorption and breathing performance of $\left\{[\mathrm{Mn}(\mathrm{imH})]_{2}\left[\mathrm{Mo}(\mathrm{CN})_{8}\right]\right\}_{\mathrm{n}}$ matches or even outperforms MOFs that are typically designed/selected for water harvesting applications with perfect sorption reversibility and very low desorption temperatures. Moreover, the sorption and breathing of $\mathbf{1 M n}$ occurs in three well-defined steps (quasi phase transitions) with four different crystal phases studied structurally by powder X-ray diffraction leading to a complete understanding of the sorption mechanism. The capture/release of $\mathrm{H}_{2} \mathrm{O}$ by $\mathbf{1 M n}$ switches also the EPR signal intensity of the $\mathrm{Mn}^{\mathrm{II}}$ centers, which has been demonstrated by in-situ EPR measurements at room temperature during the sorption/desorption process and enables monitoring of the hydration level of $\mathbf{1 M n}$ by EPR. The hydration level of $\mathbf{1 M n}$ controls also its photomagnetic behavior at the cryogenic regime, thanks to the presence of the $\left[\mathrm{Mo}^{\mathrm{IV}}(\mathrm{CN})_{8}\right]^{4-}$ photomagnetic chromophores in the structure. These observations demonstrate for the first time the extraordinary sorption potential of cyanide-bridged CPs and the possibility to merge it with the unique physical properties of this class of compounds arising from their bimetallic character (e.g. photomagnetism and long-range magnetic ordering).
\end{abstract}

\section{Introduction}

Metal-organic frameworks (MOFs) dominated the field of porous molecule-based materials due to their outstanding sorption characteristics ${ }^{1,2}$ including the capture of small molecules (e.g. $\left.\mathrm{H}_{2}, \mathrm{CO}_{2}, \mathrm{CH}_{4}\right),{ }^{3-7}$ water, ${ }^{8,9}$ alcohols ${ }^{10-13}$ or compounds as large as $\operatorname{aromatics}^{14,15}$ or proteins. ${ }^{16,17}$ Some of the recent advancements in this field cover exceptional water harvesting applications ${ }^{18-22}$ and the construction of adsorption-driven heat pumps. $^{23-25}$ Therefore, it is widely believed that MOFs outperform other water sorption materials, as they can indeed absorb moisture at much lower vapor pressures than active carbons and may be regenerated at significantly lower temperatures than silica gels or zeolites. Nonetheless, MOFs are currently being challenged by covalent organic frameworks (COFs), ${ }^{26-29}$ which in principle are more stable against $\mathrm{H}_{2} \mathrm{O}$, as opposed to the hydrolysis susceptible metal-carboxylate moieties present in MOFs. ${ }^{30}$

In this whirlwind of $\mathrm{MOF} / \mathrm{COF}$ possibilities, $\mathrm{CN}$ bridged coordination polymers (CN-CPs) - Prussian Blue Analogs (PBAs) and related cyanide-bridged frameworks - remain underrated or even omitted as potential sorbents despite some promising reports of $\mathrm{H}_{2}{ }^{31-34}$ and ammonia ${ }^{35-37}$ sorption. This is caused by another common belief that these materials show low fatigue resistance limited to several sorption cycles and can release toxic components in the process - like the first examples of MOFs before the seminal work by Yaghi et al. ${ }^{38}$ and before the demonstration of reversible bond breaking in the water-stable DMOF-TM showing state-of-the-art water sorption capabilities. ${ }^{39}$ Overcoming this stereotype is crucial for further progress in the field of multifunctional molecular materials as $\mathrm{CN}$ CPs offer the possibility of fine tuning of many different functionalities including magnetism or magnetic and photomagnetic switching upon solvent removal/exchange. ${ }^{40-47}$ This in turn will potentially lead to ground-breaking magnetic sponge systems $^{48,49}$ operational at room temperature.

In this work, we address this issue by presenting stateof-the-art water sorption properties and exceptional cyclability of a completely nonporous cyanide-bridged framework $\left\{\left[\mathrm{Mn}^{\mathrm{II}}(\mathrm{imH})\right]_{2}\left[\mathrm{Mo}^{\mathrm{IV}}(\mathrm{CN})_{8}\right]\right\}_{\mathrm{n}}(\mathbf{1 M n})$, the analog of the lowtemperature magnetic sponge-like system $\left\{\left[\mathrm{Mn}^{\mathrm{II}}(\mathrm{imH})\right]_{2}\left[\mathrm{Nb}^{\mathrm{IV}}(\mathrm{CN})_{8}\right]\right\}_{\mathrm{n}}{ }^{45}$ and the photomagnetic sponge $\left\{\left[\mathrm{Mn}^{\mathrm{II}}(\mathrm{imH})\right]_{2}\left[\mathrm{~W}^{\mathrm{IV}}(\mathrm{CN})_{8}\right]\right\}_{\mathrm{n}} \cdot{ }^{47}$ Despite the obvious lack of porosity demonstrated in the nitrogen sorption experiment, 1Mn shows three water-induced quasi-phase transitions, 
a)

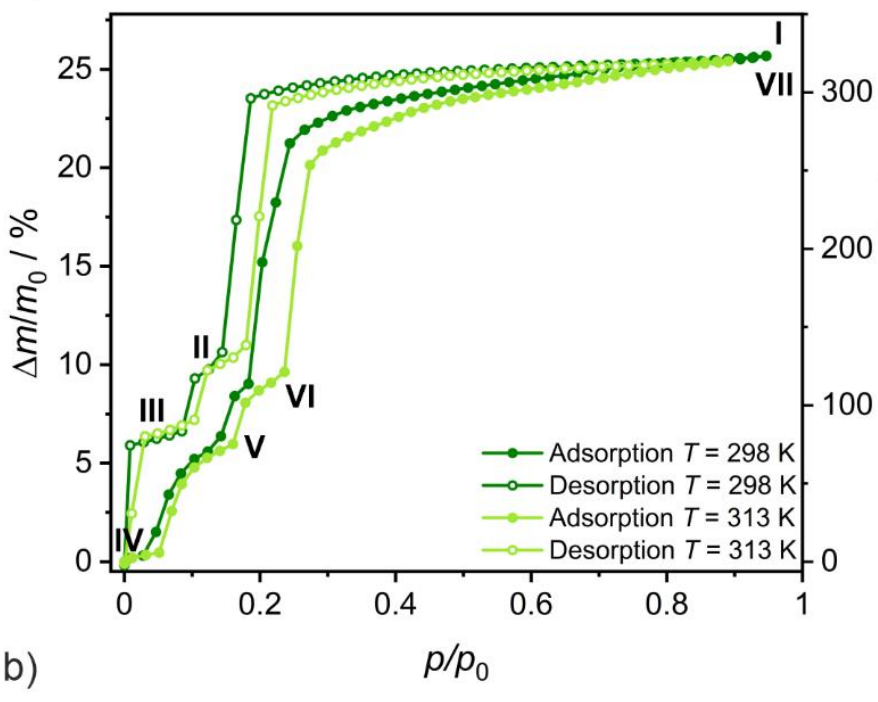

b)

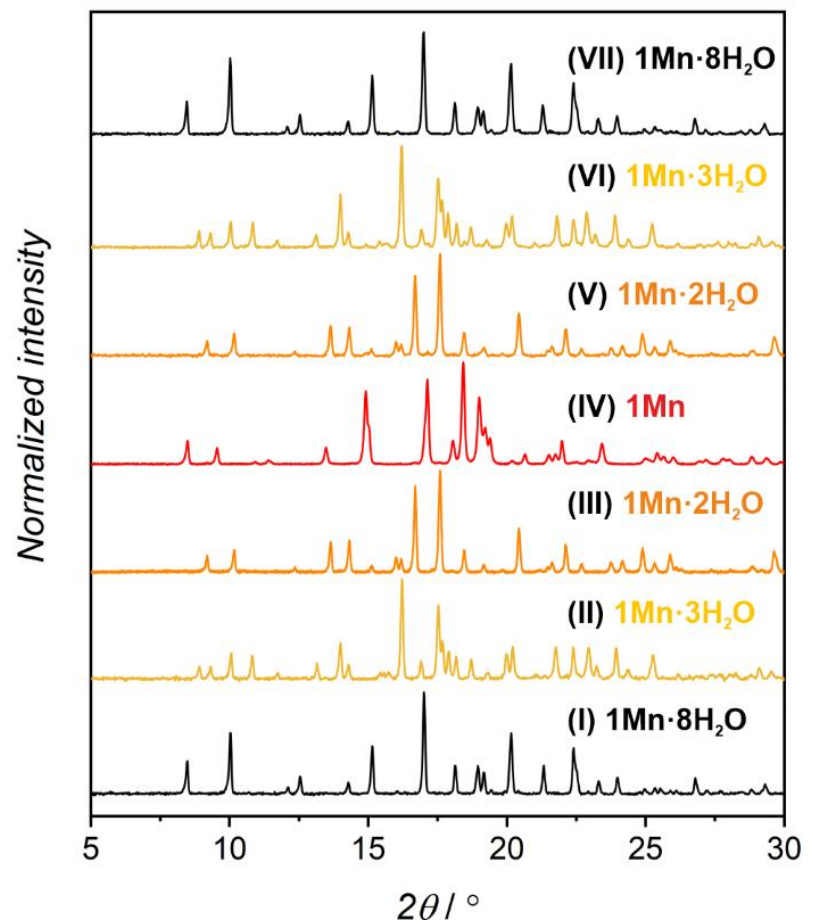

c)

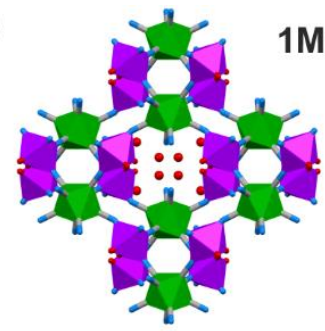

$1 \mathrm{Mn} \cdot 8 \mathrm{H}_{2} \mathrm{O}$

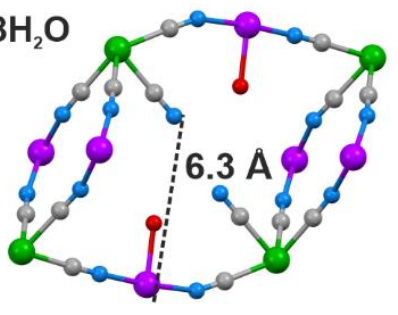

$\uparrow$

d)

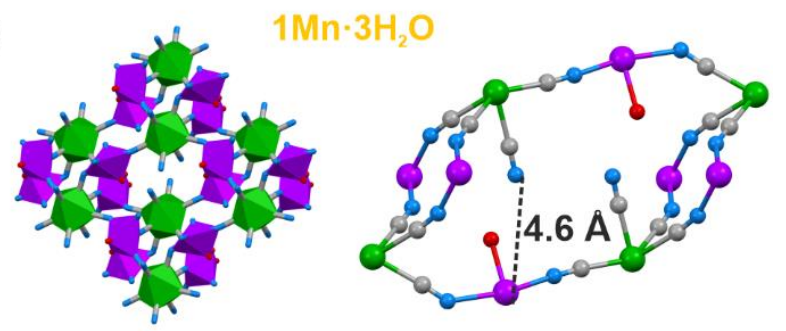

$\uparrow$

e)

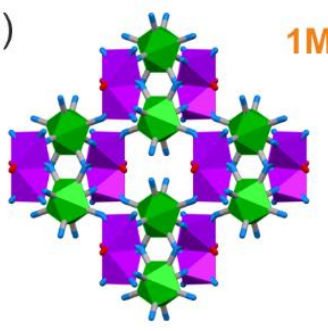

$1 \mathrm{Mn} \cdot 2 \mathrm{H}_{2} \mathrm{O}$

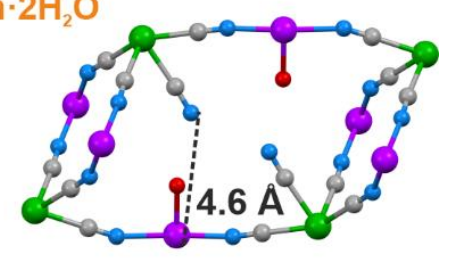

$\uparrow$

f)

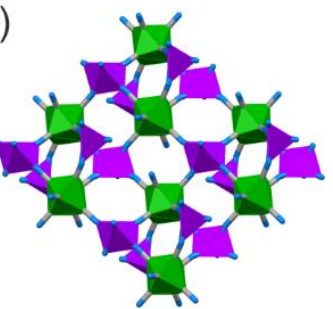

$1 \mathrm{Mn}$

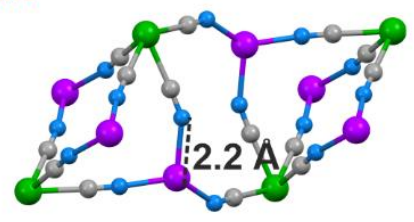

Figure 1. a) Water sorption/desorption isotherms for $\mathbf{1} \mathbf{M n} \cdot \mathbf{8} \mathbf{H}_{\mathbf{2}} \mathbf{O}$ at $298 \mathrm{~K}$ and $313 \mathrm{~K}$. Roman numbers enumerate different dehydration/hydration stages. b) PXRD patterns observed for phases denoted in Figure 1a. c)-f) Schematic representation of structural changes occurring during $\mathbf{1} \mathbf{M n} \cdot \mathbf{8} \mathbf{H}_{\mathbf{2}} \mathbf{O}$ transformation between different crystalline phases. Imidazole molecules and hydrogen atoms were omitted for clarity.

accompanied by a very large breathing effect $\mathrm{t}^{50-52}$ and a substantial change in the cyanide bridging pattern fully understood based on the powder X-ray diffraction structural analysis. The three-step breathing process is fully reversible and exceptionally fatigue resistant over tens of sorption/desorption cycles, with the complete preservation of crystallinity and very high water uptake exceeding $25 \% \mathrm{w} / \mathrm{w}$.

Beside exceptional water sorption and cyclability, 1Mn exhibits marked magnetic and photomagnetic changes upon water capture. Similar effects were previously reported in paramagnetic MOFs where strong interdependence between sorption and other physical properties occurs. ${ }^{53-60}$ In some cases, the profound structural and electronic changes induced by guest molecules enable the characterization/monitoring of the sorption process using EPR spectroscopy. This can be done directly in the case of paramagnetic guests ${ }^{61-65}$ or indirectly by analyzing the $g$-factor shift of paramagnetic metal centers as in some $\mathrm{Cu}^{\mathrm{II}}$-based porous materials. ${ }^{58,66-68}$ Noteworthy, EPR spectroscopy is commonly applied to study the state of the paramagnetic active sites doped into the mesoporous hosts such as zeolites in various catalytic processes. ${ }^{69-72}$ In the case of $\mathbf{1 M n}$, presented herein, the state of the $\mathrm{Mn}^{\mathrm{II}}$ sites was successfully monitored in the real time by employing in situ EPR spectroscopy during the sorption/desorption of water molecules. Structural and electronic changes within the coordination sphere of $\mathrm{Mn}^{\mathrm{II}}$ affects also the low-temperature photo-induced magnetization of the compound which is evidenced by detailed photomagnetic studies. 


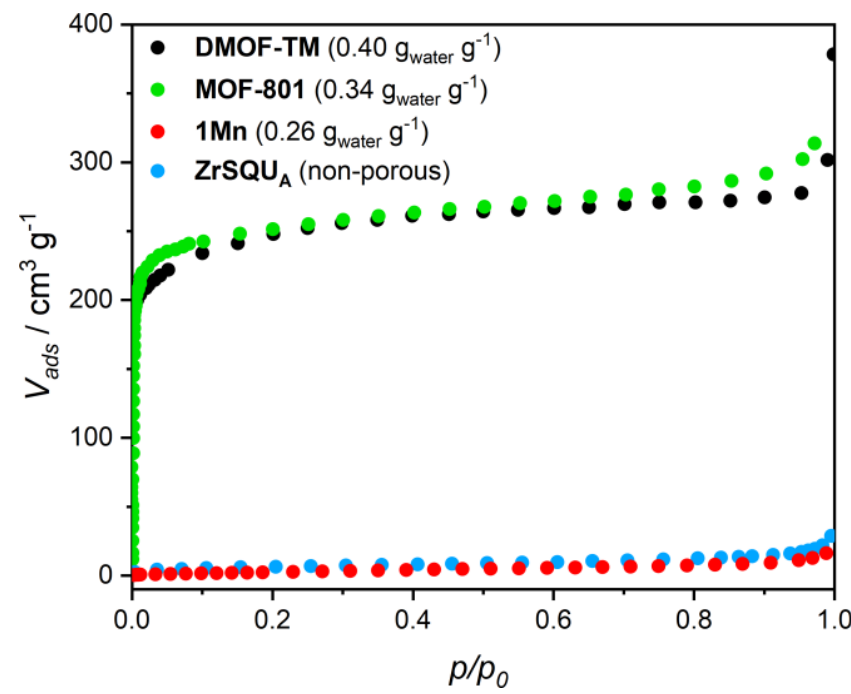

Figure 2. Nitrogen adsorption isotherms at $77 \mathrm{~K}$ for $\mathbf{1 M n}$ and selected MOFs. Water loading values at $p / p_{0}=0.9$ and $T=298 \mathrm{~K}$ presented in the parentheses were reported in ref. ${ }^{39}$ for DMOF-TM and ref. 9 for MOF801. BET isotherms for MOFs were adapted from refs ${ }^{39},{ }^{73}$ and ${ }^{74}$.

\section{Results and discussion}

$\left\{\left[\mathrm{Mn}^{\mathrm{II}}(\mathrm{imH})\left(\mathrm{H}_{2} \mathrm{O}\right)_{2}\right]_{2}\left[\mathrm{Mo}^{\mathrm{IV}}(\mathrm{CN})_{8}\right] \cdot 4 \mathrm{H}_{2} \mathrm{O}\right\}_{\mathrm{n}}\left(\mathbf{1} \mathbf{M n} \cdot \mathbf{8} \mathbf{H}_{2} \mathrm{O}\right)$ was prepared according to the modified literature procedure ${ }^{75}$ by combining water solutions of manganese(II) chloride and imidazole with potassium octacyanomolybdate(IV), affording yellow crystals suitable for single crystal X-ray diffraction (SCXRD; see Experimental section for details). $\mathbf{1 M n} \cdot \mathbf{8} \mathbf{H}_{2} \mathrm{O}$ forms a three-dimensional coordination framework in $C 2 / c$ space group, with two octahedral manganese(II) cations surrounded by an imidazole ligand disordered between two positions, three nitrogen atoms of $\left[\mathrm{Mo}^{\mathrm{IV}}(\mathrm{CN})_{8}\right]^{4-}$ in a mer configuration and two coordinated water molecules in cis disposition (Figure S1). Each octacyanidomolybdate(IV) connects six manganese(II) centers and the $\mathrm{Mn}_{2} \mathrm{Mo}$ unit is accompanied by four crystallization water molecules located in the channels along the crystallographic $c$ direction (Figure 1c).

The coordination and crystallization water molecules can be removed completely by heating $1 \mathrm{Mn} \cdot 8 \mathrm{H}_{2} \mathrm{O}$ above $60^{\circ} \mathrm{C}$ in a dry nitrogen atmosphere, and the coordination skeleton of the resulting $\left\{\left[\mathrm{Mn}^{\mathrm{II}}(\mathrm{imH})\right]_{2}\left[\mathrm{Mo}^{\mathrm{IV}}(\mathrm{CN})_{8}\right]\right\}_{\mathrm{n}}(\mathbf{1 M n})$ remains stable up to $250{ }^{\circ} \mathrm{C}$ (TGA, Figure S2). Interestingly, water sorption/desorption isotherm recorded at $298 \mathrm{~K}$ shows that the solvent loss is in fact a three-step process (Figure 1a), proceeding through two intermediate phases. In the desorption branch, the $\mathbf{1 M n} \cdot \mathbf{8} \mathbf{H}_{2} \mathrm{O}$ phase is stable down to ca. $20 \%$ of the relative humidity (RH). The first intermediate mass plateau is observed in the $10-14 \% \mathrm{RH}$ range corresponding to $\Delta m / m_{0}$ of $9.3-10.6 \%$ (Figure 1a, II; $\Delta m / m_{0}$ denotes mass change relative to the anhydrous state, $\left.m_{0}\right)$. This step is in good agreement with $\left\{\left[\mathrm{Mn}^{\mathrm{II}}(\mathrm{imH})\left(\mathrm{H}_{2} \mathrm{O}\right)_{2}\right]\left[\mathrm{Mn}^{\mathrm{II}}(\mathrm{imH})\left(\mathrm{H}_{2} \mathrm{O}\right)\right]\left[\mathrm{Mo}^{\mathrm{IV}}(\mathrm{CN})_{8}\right]\right\}_{\mathrm{n}}$ composition (calculated $\Delta m / m_{0}=9.8 \%$ corresponds to 3 water molecules), which would account for simultaneous removal of four crystallization water molecules and one coordinated water molecule. Indeed, powder X-ray diffraction (PXRD) confirms the appearance of a new crystalline phase $\mathbf{1} \mathbf{M n} \cdot \mathbf{3} \mathbf{H}_{2} \mathrm{O}$ obtained under conditions corresponding to point II in Figure 1a (Figure 1b,
II). Upon further decrease in relative humidity down to 1-8 \% $\mathrm{RH}$ range, another mass plateau emerges for $\Delta m / m_{0}=6.1-6.6 \%$ (Figure 1a, III), which is close to $6.5 \%$ predicted for $\left\{\left[\mathrm{Mn}^{\mathrm{II}}(\mathrm{imH})\left(\mathrm{H}_{2} \mathrm{O}\right)\right]_{2}\left[\mathrm{Mo}^{\mathrm{IV}}(\mathrm{CN})_{8}\right]\right\}_{\mathrm{n}}\left(\mathbf{1} \mathbf{M n} \cdot \mathbf{2} \mathbf{H}_{2} \mathrm{O}\right)$. The PXRD experiment shows complete disappearance of $\mathbf{1} \mathbf{M n} \cdot \mathbf{3} \mathrm{H}_{2} \mathrm{O}$ reflections at this step and the emergence of a new powder pattern for $\mathbf{1} \mathbf{M n} \cdot \mathbf{2} \mathbf{H}_{2} \mathrm{O}$ is depicted in Figure 1b, III. Passing dry nitrogen over the sample produces anhydrous $\mathbf{1 M n}$, accompanied by the final changes in the PXRD pattern (Figure 1b, IV). The rehydration process shows distinct hysteresis in water sorption isotherm, yet powder X-ray diffraction confirms that it proceeds through the same crystalline phases as during dehydration (Figures 1a and 1b: V, VI and VII). Overall, the stepwise water adsorption isotherm for $\mathbf{1 M n}$ at $298 \mathrm{~K}$ shows the water uptake of $0.26 \mathrm{~g}_{\text {water }} \mathrm{g}^{-1}$ at $p / p_{0}=0.9$, but already reaches $0.225 \mathrm{~g} \mathrm{~g}^{-1}$ at $p / p_{0}$ $=0.3$.

Upon solvent removal crystals of $\mathbf{1} \mathbf{M n} \cdot \mathbf{8} \mathbf{H}_{2} \mathrm{O}$ crack, precluding determination of crystal structure by means of SCXRD. Therefore structures of compounds $1 \mathrm{Mn} \cdot 3 \mathrm{H}_{2} \mathrm{O}, \mathbf{1 M n} \cdot \mathbf{2} \mathrm{H}_{2} \mathrm{O}$ and $\mathbf{1 M n}$ were modeled by Rietveld refinement of respective PXRD patterns (Figures S3-S5). In the first step of the dehydration, the water-filled channels of $\left\{\left[\mathrm{Mn}^{\mathrm{II}}(\mathrm{imH})\left(\mathrm{H}_{2} \mathrm{O}\right)_{2}\right]_{2}\left[\mathrm{Mo}^{\mathrm{IV}}(\mathrm{CN})_{8}\right]\right\}_{\mathrm{n}^{-}}$ $\cdot 4 \mathrm{H}_{2} \mathrm{O}$ are emptied and one coordinated water molecule per formula unit is removed (Figure 1c-d), which leads to a $14.0 \%$ shrinkage of the unit cell. Thus, the symmetry equivalent manganese(II) centers are diversified into the distorted octahedral $\left[\mathrm{Mn}^{\mathrm{II}}(\mathrm{imH})\left(\mathrm{H}_{2} \mathrm{O}\right)_{2}(\mu-\mathrm{NC})_{3}\right]$ and trigonal bipyramidal $\left[\mathrm{Mn}^{\mathrm{II}}(\mathrm{imH})\left(\mathrm{H}_{2} \mathrm{O}\right)(\mu-\mathrm{NC})_{3}\right]$ moieties in the resulting $\left\{\left[\mathrm{Mn}^{\mathrm{II}}(\mathrm{imH})\left(\mathrm{H}_{2} \mathrm{O}\right)_{2}\right]\left[\mathrm{Mn}^{\mathrm{II}}(\mathrm{imH})\left(\mathrm{H}_{2} \mathrm{O}\right)\right]\left[\mathrm{Mo}^{\mathrm{IV}}(\mathrm{CN})_{8}\right]\right\}_{\mathrm{n}}$ framework. This decreases the lattice symmetry down to $P \overline{1}$ space group. The removal of an additional coordinated water molecule restores the $C 2 / c$ symmetry, by converting the remaining six-coordinated manganese(II) into a trigonal bipyramidal motif in the $\left\{\left[\mathrm{Mn}^{\mathrm{II}}(\mathrm{imH})\left(\mathrm{H}_{2} \mathrm{O}\right)\right]_{2}\left[\mathrm{Mo}^{\mathrm{IV}}(\mathrm{CN})_{8}\right]\right\}_{\mathrm{n}}$ framework (Figure 1e). In this step, only a minimal change of the unit cell volume is observed $(-1.6 \%)$. The most pronounced transformation is observed in the last dehydration step. Removal of the remaining two aqua ligands enables the formation of the additional cyanide bridge in $\left\{\left[\mathrm{Mn}^{\mathrm{II}}(\mathrm{imH})\right]_{2}\left[\mathrm{Mo}^{\mathrm{IV}}(\mathrm{CN})_{8}\right]\right\}_{\mathrm{n}}$, enforcing further $11.7 \%$ decrease in the unit cell volume. In the final structure (triclinic, $P \overline{1}$, Figure 1f) the tetracoordinate $\left[\mathrm{Mn}^{\mathrm{II}}(\mathrm{imH})(\mu\right.$ $\mathrm{NC})_{3}$ ] adopts distorted vacant trigonal bipyramidal geometry and the pentacoordinate $\left[\mathrm{Mn}^{\mathrm{II}}(\mathrm{imH})(\mu-\mathrm{NC})_{4}\right]$ center becomes a distorted trigonal bipyramid. Each octacyanidomolybdate(IV) unit forms seven cyanide bridges to the neighboring manganese(II) centers in the anhydrous form. The aforementioned dehydration-driven stepwise transformations are mirrored in the rehydration experiments, as depicted in Figures $1 \mathrm{a}$ and $1 \mathrm{~b}$. The unit cell volume per formula unit changes from $996 \AA^{3}$ in $\mathbf{1 M n}$ to $1332 \AA^{3}$ in $\mathbf{1} \mathbf{M n} \cdot \mathbf{8} \mathbf{H}_{\mathbf{2}} \mathbf{O}$, which accounts for the $34 \%$ total change between the anhydrous and the fully hydrated phases, respectively. Such tremendous unit cell expansion is unprecedented among other porous cyanide-bridged polymers ${ }^{46,76-84}$ and falls within the range observed for flexible $\mathrm{MOFs}^{52}$. Interestingly, the structure of the anhydrous 1Mn does not show any solvent accessible voids and hence - no permanent porosity. This is evidenced by type II nitrogen 
a)

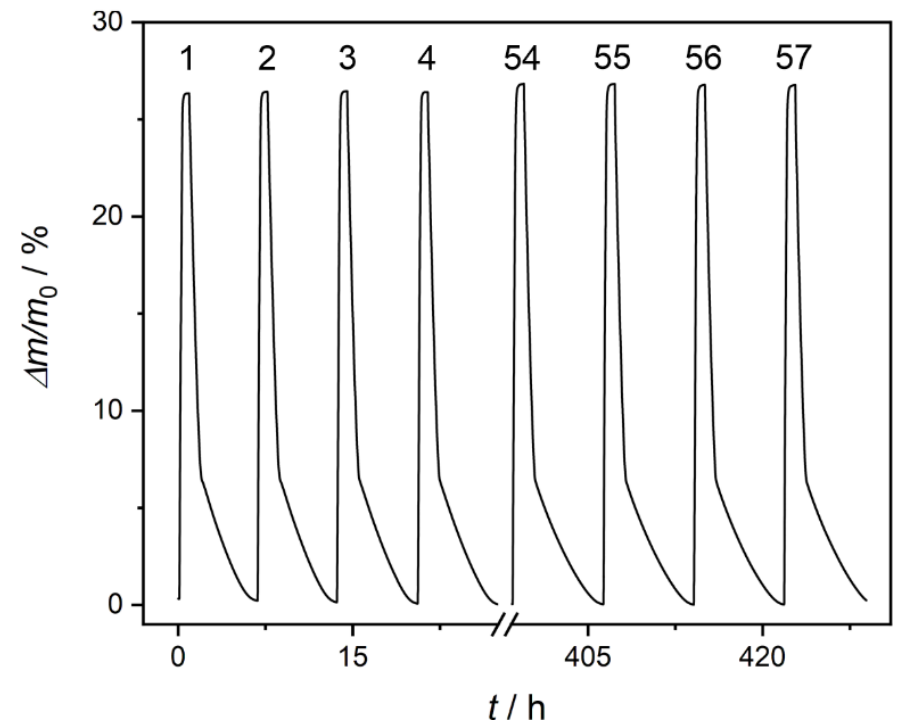

b)

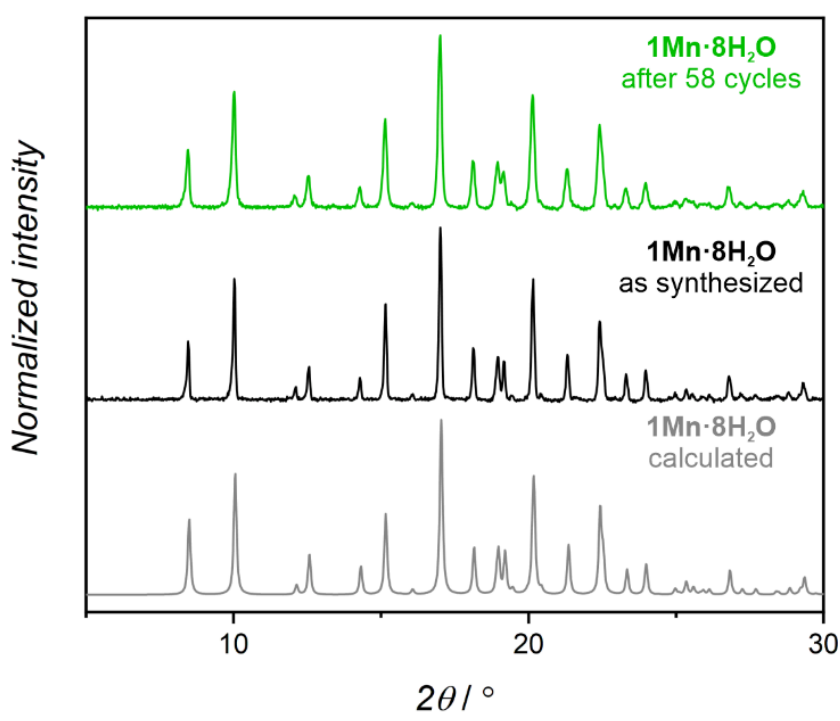

Figure 3. a) Water cycling stability test ( $0 \%$ RH dehydration $-95 \%$ RH rehydration) of $\mathbf{1} \mathbf{M n} \cdot \mathbf{8} \mathbf{H}_{2} \mathbf{O}$ at $298 \mathrm{~K}$ (numbers above the curve enumerate the consecutive dehydration-rehydration cycles; Figure S6 shows all 57 cycles). b) Powder X-ray diffraction patterns for $\mathbf{1} \mathbf{M n} \cdot \mathbf{8} \mathbf{H}_{2} \mathbf{O}$ : calculated from the singlecrystal structure (grey), experimental for pristine sample (black) and experimental after 58 dehydration-rehydration cycles (green).

adsorption isotherm recorded at $77 \mathrm{~K}$ (Figure 2 ). The observed $\mathrm{N}_{2}$ uptake of $16 \mathrm{~cm}^{3} \mathrm{~g}^{-1}$ at $p / p_{0}=1.0$ is an order of magnitude smaller than observed for MOFs showing similar total water uptake (such as DMOF-TM ${ }^{39,85}$ or MOF-801 ${ }^{9,73}$ ) and even smaller than reported for the typically non-porous materials such as $\mathrm{Zr}_{6} \mathrm{O}_{4}(\mathrm{OH})_{4}(\mathrm{SQU})_{5.25}\left(\mathrm{CH}_{3} \mathrm{COO}\right)_{1.5}$ MOF based on a squaric $\mathrm{acid}^{74}$. Therefore combined structural and sorption studies of 1Mn show that initial chemisorption of four water molecules opens the channels in its structure, which only then enables physisorption of the remaining water. Although similar water-induced gate-opening behavior was previously reported for JUK$8,{ }^{86}$ SIFSIX-23-Cu ${ }^{87}$ and the MIL-53 family, ${ }^{88-90}$ to the best of our knowledge 1Mn constitutes the first case among non-reticular materials.

$\mathbf{1} \mathbf{M n} \cdot \mathbf{8} \mathrm{H}_{2} \mathrm{O}$ shows marvelous stability during dehydration-rehydration cycling taking into account the accompanying huge unit cell volume variations. This was confirmed by dynamic vapor sorption experiments. The sample mass was monitored as the relative humidity was switched between 0 and $95 \%$ at 298 $\mathrm{K}$ in 57 cycles (Figure 3a; see Figure S6 for full representation of 57 adsorption-desorption cycles). The observed mass change of $26.7 \%$ between 0 and $95 \% \mathrm{RH}$ agrees perfectly with the value of $26.2 \%$ expected for transition between $\mathbf{1 M n}$ and $\mathbf{1 M n} \cdot \mathbf{8 H}_{2} \mathrm{O}$. No change in the curve profile is observed in 57 cycles performed over the course of 430 hours. Powder X-ray diffraction pattern collected for the sample rehydrated after the end of the cycling experiment shows no difference from the one recorded for the pristine sample at the beginning of the experiment (Figure 3b). Apart from the apparent broadening of the diffraction peaks, the PXRD patterns of the fully hydrated samples before and after the cycling experiment do not show any significant differences (see Figure S7). The peak broadening can be explained by the decrease in the grain size resulting from the repetitive breaking of the crystallites in the consecutive dehydration/rehydration cycles. Nonetheless, both DVS and PXRD experiments confirm the perfect stability of the material in water sorption experiments, with full retainment of its water uptake and crystallinity after at least 58 cycles.
High water-stability and water uptake at low relative pressures are required for application in atmospheric water harvesting. ${ }^{9,91}$ For this purpose materials with low desorption temperatures are preferable, in order to easily retrieve a liquid condensate from the hydrated sorbent. By comparing the adsorption isotherms at $25{ }^{\circ} \mathrm{C}$ and $40{ }^{\circ} \mathrm{C}$ (Figure S8), we conclude that the material should produce around $0.172 \mathrm{~g}_{\text {water }} \mathrm{g}^{-1}$ under $0.95 \mathrm{kPa}$ water pressure $\left(30 \% \mathrm{RH}\right.$ at $\left.25^{\circ} \mathrm{C}\right)$ upon cycling between these two temperatures. Such a process should switch the material between the $\mathbf{1} \mathbf{M n} \cdot \mathbf{8} \mathbf{H}_{2} \mathrm{O}$ and $\mathbf{1} \mathbf{M n} \cdot \mathbf{2} \mathbf{H}_{2} \mathrm{O}$ hydration states with a simultaneous release of all crystallization water molecules and a half of the coordinated ones at only $40{ }^{\circ} \mathrm{C}$. To confirm that 1Mn can be used for moisture harvesting, we performed a cycling experiment which emulates desert conditions in the daytime $\left(40{ }^{\circ} \mathrm{C}, 10 \% \mathrm{RH}\right)$ and at night $\left(25^{\circ} \mathrm{C}, 30 \% \mathrm{RH}\right.$; Figure S9). ${ }^{9}$ The cycling process revealed a real working capacity of $0.164 \mathrm{~g} \mathrm{~g} \mathrm{~g}^{-1}$ which approaches the theoretical value deduced from the adsorption isotherms. The observed release of chemisorbed water at low temperatures is surprising, as chemisorption is usually associated with high adsorption enthalpy. Therefore we decided to estimate the average adsorption enthalpy of water in $\mathbf{1 M n}$ by employing the van't Hoff equation to the water adsorption isotherms, as well as integrating differential scanning calorimetry (DSC) curve obtained during the sample dehydration (Figures S10-11, see the experimental section for details). Both methods give similar results, with adsorption enthalpy of $66 \mathrm{~kJ} \mathrm{~mol}^{-1}$ per water molecule deduced from the van't Hoff equation and $64 \mathrm{~kJ} \mathrm{~mol}^{-1}$ obtained from the DSC experiment. The small discrepancy results from the difference in desorption temperatures $\left(25-40^{\circ} \mathrm{C}\right.$ for the isotherm method, above $70{ }^{\circ} \mathrm{C}$ for the DSC experiment). The obtained 64-66 kJ mol ${ }^{-1}$ range is much higher than reported for hydrophilic $\mathrm{MOFs}^{24}$ and in line with the chemisorption of half of the water molecules. Nonetheless, the strong binding of water does not prevent its easy 


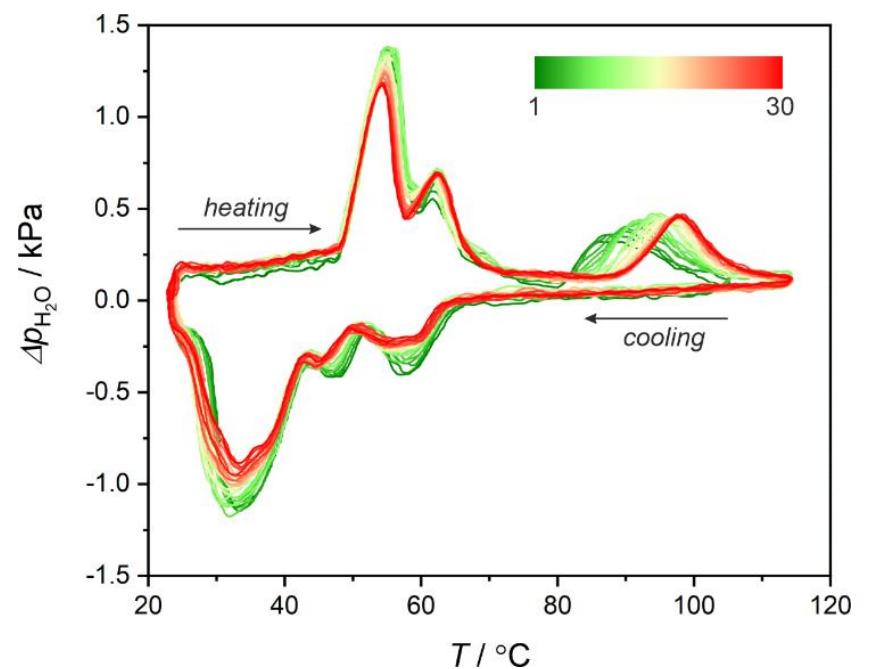

Figure 4. QE-TPDA profiles obtained for $\mathbf{1 M n} \cdot \mathbf{8} \mathrm{H}_{2} \mathrm{O}$ at a temperature sweep rate of $0.75^{\circ} \mathrm{C} /$ min using $\mathrm{H}_{2} \mathrm{O}(2.4 \mathrm{kPa}) / \mathrm{He}$ mixture as a carrier gas. removal at low temperatures, as demonstrated in the previous parts of the manuscript. This must be associated with fast desorption kinetics, which can be quantified assuming first order kinetics of dehydration and applying the Kissinger equation ${ }^{92,93}$ to the TGA results at different heating rates (Figures S12-14):

$$
\ln \frac{\beta}{T_{m}^{2}}=\text { const }-\frac{E_{a}}{R T_{m}}
$$

where $\beta$ - heating rate, $T_{\mathrm{m}}$ - the temperature at the maximum rate of mass change $(\mathrm{d} m / \mathrm{d} T)$, and $E_{\mathrm{a}}-$ activation energy. This method yields apparent activation energy of 101(7) $\mathrm{kJ} \mathrm{mol}^{-1}$ in the first dehydration step, which in the TGA experiment accounts for $\mathbf{1 M n} \cdot \mathbf{8} \mathbf{H}_{2} \mathrm{O} \rightarrow \mathbf{1 M n} \cdot \mathbf{2} \mathbf{H}_{2} \mathrm{O}$ transformation and 65(3) $\mathrm{kJ} \mathrm{mol}^{-1}$ in the second dehydration step, which ends in the production of anhydrous $\mathbf{1} \mathbf{M n}$. While the first value is within the 91-111 kJ mol ${ }^{-1}$ range reported for functionalized MIL-101Cr, ${ }^{24}$ the second value is unexpectedly small and approaching water adsorption enthalpy for $\mathbf{1 M n}$ at low water loadings. We hypothesize that this is the effect of the cyanide bridge formation in the $\mathbf{1} \mathbf{M n} \cdot \mathbf{2} \mathbf{H}_{2} \mathrm{O} \rightarrow \mathbf{1 M n}$ step, which leads to the network contraction and "squeezes" the remaining water out.

Water sorption in $\mathbf{1 M n}$ was also tested by quasi-equilibrated temperature programmed desorption and adsorption (QETPDA $)^{94-96}$. In this method, the sorption of volatile compounds is studied by cyclic heating and cooling of a quartz tube containing the sample, under the flow of adsorbate (in this case water vapor) dispersed in a stream of helium gas. The QETPDA profiles present positive signals when excess water is desorbed from the sample or negative signals when carrier gas is being depleted of the adsorbate. Recently, the method has been proven useful in studies of water sorption in MOFs ${ }^{97,98}$ and cyanide-bridged assemblies ${ }^{99}$. The QE-TPDA profiles of $\mathbf{1 M n} \cdot \mathbf{8} \mathbf{H}_{2} \mathrm{O}$ demonstrate a three-step desorption process (Figure 4), which is in line with the aforementioned water desorption isotherm. While the first two steps remain almost unchanged in the 30 consecutive sorption/desorption cycles, the high-temperature one, corresponding to the $\mathbf{1} \mathbf{M n} \cdot \mathbf{2} \mathbf{H}_{2} \mathbf{O} \rightarrow \mathbf{1 M n}$ transformation, drifts to higher temperatures from $86^{\circ} \mathrm{C}$ in the first cycle to a)

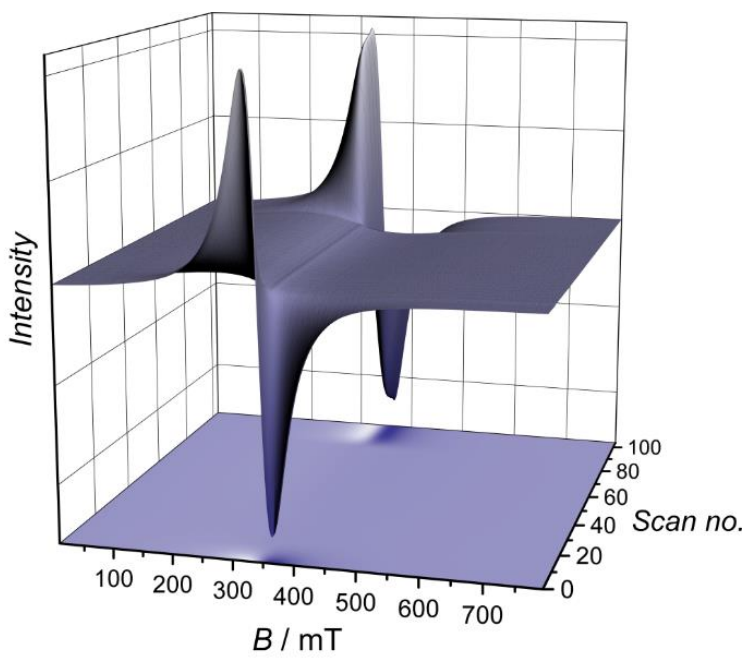

b)

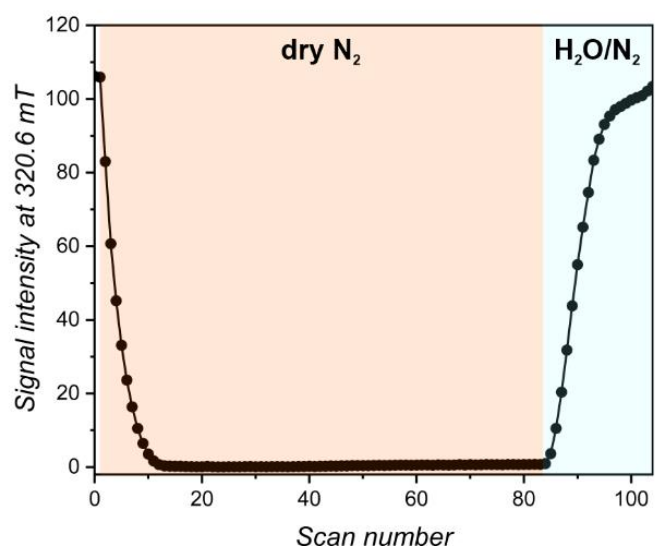

Figure 5. a) Continuous wave $\mathrm{X}$-band $(9.7 \mathrm{GHz})$ EPR spectra obtained for $\mathbf{1} \mathbf{M n} \cdot \mathbf{8} \mathbf{H}_{2} \mathrm{O}$ during dehydration (scans 0-84) and rehydration (scans 85-105) at room temperature. b) EPR signal intensity for $\mathbf{1} \mathbf{M n} \cdot \mathbf{8} \mathbf{H}_{2} \mathrm{O}$ upon dry $\mathrm{N} 2$ purging (scan numbers 0-84) and rehydration in $\mathrm{N}_{2}$ saturated with water vapor (scan numbers $85-105$ )

$98^{\circ} \mathrm{C}$ in cycles $20^{\text {th }}-30^{\text {th }}$. It is worth noting that these temperatures are higher than in the TGA experiments because in QETPDA the water vapor pressure at $20{ }^{\circ} \mathrm{C}$ is $100 \% \mathrm{RH}$ (TGA analysis is performed using dry nitrogen). The shift in the final desorption temperature is hard to explain, as no visible decrease in water loading can be deduced from the QE-TPDA signal after 30 cycles of temperature driven desorption. Powder X-ray diffractogram obtained after the experiment (30 adsorption/desorption cycles in the $23-115^{\circ} \mathrm{C}$ range) shows that the compound preserves crystallinity, but shows small unidentified reflections indicating some fatigue/damage (Figure S15). Possibly, it may indicate minor structural changes, such as the appearance of defects in the structure affecting the last desorption step. Still, the QE-TPDA analysis confirms the exceptionally good stability of $\mathbf{1 M n}$ during $23-115^{\circ} \mathrm{C}$ thermal cycling in a humid environment.

Paramagnetic manganese(II) nodes in the structure of $\mathbf{1 M n}$ make it possible to study water sorption using electron paramagnetic resonance (EPR) spectroscopy. Manganese(II) cations usually show a negligible contribution from orbital momentum, sustaining sufficiently long spin relaxation times to observe the EPR spectrum at room temperature. This is accompanied by relatively small zero field splitting 


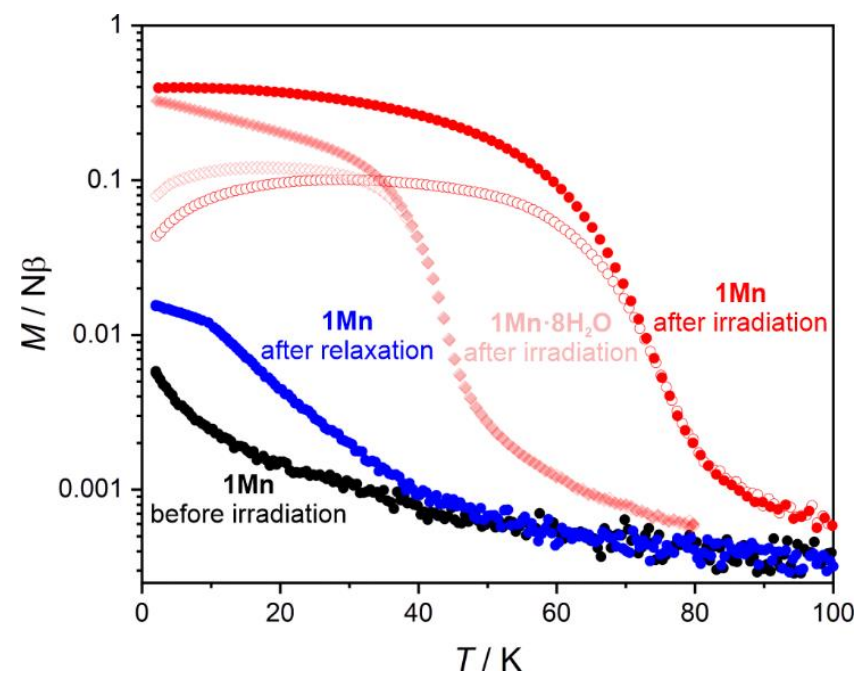

Figure 6. Field-cooled (closed symbols) and zero field-cooled (open symbols) curves for $\mathbf{1 M n}$ (circles) and $\mathbf{1} \mathbf{M n} \cdot \mathbf{8} \mathbf{H}_{2} \mathbf{O}$ (rhombi) under $H_{\mathrm{DC}}=0.02$ T. Both samples were irradiated with $\lambda=450 \mathrm{~nm}$ and $P=3-5 \mathrm{~mW}$ light, thermal relaxation for $\mathbf{1} \mathbf{M n}$ was performed by heating to $315 \mathrm{~K}$ and stabilizing at this temperature for 1 hour.

(ZFS) effect (in the range of X-band microwave frequency), which is influenced by the local coordination environment of the metal ion. Therefore EPR may be utilized to track changes in manganese(II) geometry upon solvation/desolvation at room temperature and in real time. In our experiment, powdered $\mathbf{1 M n} \cdot \mathbf{8 H} \mathrm{H}_{2} \mathrm{O}$ was subjected to a continuous flow of nitrogen (either dry or saturated with water vapors) inside the EPR resona-

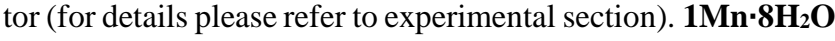
shows a broad signal at $g=2.00$ demonstrated in Figure 5a (scans 0-10) and S16, which originates from the overlap of transitions between different $m_{\mathrm{S}}$ states for $S=5 / 2$. Drying the sample leads to the rapid drop in the signal intensity and its broadening (Figure 5a). The lowest EPR signal intensity at $320.6 \mathrm{mT}$ is reached around scan no. 25 (Figure 5b and S17). The hydration stage at this step can be identified by comparison with the EPR spectra recorded for the isolated phases (Figures S16 and S18). It was assigned as a mixture of $\mathbf{1 M n} \cdot \mathbf{2} \mathbf{H}_{2} \mathbf{O}$ and $\mathbf{1} \mathbf{M n} \cdot \mathbf{3} \mathbf{H}_{2} \mathrm{O}$, in line with the DVS measurement, in which the observed mass change in the intermediate step of dry gas dehydration can be attributed to $\mathbf{1} \mathbf{M n} \cdot \mathbf{2} \mathbf{H}_{2} \mathbf{O}$ (Figure 3a). Upon further drying, the intensity of the transition slowly increases for over 50 scans (Figure $5 b$ ), which corresponds to a slow formation of the anhydrous $\mathbf{1 M n}$. Saturating purge gas with water vapors leads to a very fast signal recovery with no observation of the intermediate steps depicted in Figure $5 \mathrm{a}$, exactly as in the DVS experiment. In order to study phase-dependent variation of ZFS in $\mathbf{1 M n} \cdot \mathbf{8} \mathrm{H}_{2} \mathrm{O}$, we prepared its isomorphous cadmium analog $\left\{\left[\mathrm{Cd}(\mathrm{imH})\left(\mathrm{H}_{2} \mathrm{O}\right)_{2}\right]_{2}\left[\mathrm{Mo}^{\mathrm{IV}}(\mathrm{CN})_{8}\right] \cdot 4 \mathrm{H}_{2} \mathrm{O}\right\}_{\mathrm{n}}(\mathbf{2 C d} \cdot \mathbf{8 H} \mathbf{H}$ ) (Figure $\mathrm{S} 19)$. Resolution of six transitions resulting from hyperfine splitting caused by manganese $I=5 / 2$ nucleus was achieved for the diamagnetic matrix of $\mathbf{2} \mathbf{C d} \cdot \mathbf{8} \mathrm{H}_{2} \mathrm{O}$ doped with manganese(II) (2Cd·8H2O:Mn), but left ZFS unresolved (Figure S20). This suggests only minimal zero-field splitting, which was estimated using EasySpin software ${ }^{100}$ to be no larger than $|D|=0.04 \mathrm{~cm}^{-1}$. Unlike $\mathbf{1} \mathbf{M n} \cdot \mathbf{8} \mathbf{H}_{2} \mathrm{O}$, dehydration of $\mathbf{2 C d} \cdot \mathbf{8} \mathbf{H}_{2} \mathrm{O}$ leads to amorphization and decomposition, which is observed in the TGA measurement at the temperature ca. $80{ }^{\circ} \mathrm{C}$ lower than for the Mn-analog (Figure S1). Nevertheless, the crystallinity of the dry amorphous solid dried under vacuum at room temperature can be restored by rehydration at $100 \% \mathrm{RH}$ (Figure
S21). Despite the restoration of the crystallinity, the water sorption capacity of $\mathbf{2 C d}$ decreases significantly in the subsequent QE-TPDA sweeps (Figure S22), foreshadowing irreversible damage of the coordination skeleton. Amorphization is even more pronounced for $\mathbf{2} \mathbf{C d} \cdot \mathbf{8} \mathbf{H}_{2} \mathrm{O}: \mathbf{M n}$, which after dehydration shows no diffraction peaks in the PXRD experiment (Figure S23). Thus, we were unable to determine the exact parameters of ZFS for $\mathbf{1 M n}, \mathbf{1} \mathbf{M n} \cdot \mathbf{2} \mathbf{H}_{2} \mathrm{O}$ and $\mathbf{1} \mathbf{M n} \cdot \mathbf{3} \mathbf{H}_{2} \mathrm{O}$ by studying the Mn-doped Cd-analogs as the corresponding crystalline phases could not be identified. This highlights the key role of manganese(II) for the stabilization and "breathing" performance of the $\mathrm{CN}$-bridged framework upon water sorption/desorption. Apparently, manganese(II) not only provides paramagnetic properties of the material but is responsible for the structural integrity of the framework.

Results of the EPR spectroscopy are fully supported by magnetometry of $\mathbf{1 M n}$ and its hydrated states, as depicted in Figures S24-25. Room-temperature $\chi T$ products for all four compounds are within $8.8-9.0 \mathrm{~cm}^{3} \mathrm{~K} \mathrm{~mol}^{-1}$ range, as expected for two independent manganese(II) cations characterized by $g=2.0$. The $\chi T(T)$ curves show a distinct decrease at the lowest temperatures, which is more pronounced for more dehydrated phases. It can be ascribed to increasing ZFS and stronger antiferromagnetic interactions, due to the decreasing distances between $\mathrm{Mn}(\mathrm{II})$ centers associated with dehydration and unit cell volume contraction. A similar effect is observed for $M(H)$ dependencies, which show deviation from Brillouin function that becomes more distinct with the dehydration level in the $\mathbf{1 M n} \cdot 8 \mathrm{H}_{2} \mathrm{O} \rightarrow \mathbf{1 M n} \cdot 3 \mathrm{H}_{2} \mathrm{O} \rightarrow \mathbf{1 M n} \cdot 2 \mathrm{H}_{2} \mathrm{O} \rightarrow 1 \mathrm{Mn}$ series. Nonetheless, all phases behave as paramagnets in the whole 2$300 \mathrm{~K}$ range, as expected for manganese(II) cations separated by diamagnetic octacyanomolybdate(IV) groups.

The octacyanomolybdate(IV) anion was previously demonstrated to behave as an intrinsic photomagnetic chromophore in several bimetallic CN-bridged systems. ${ }^{101-103}$ Therefore we decided to study the photomagnetic properties of $\mathbf{1 M n}$ and $\mathbf{1 M n} \cdot \mathbf{8} \mathrm{H}_{2} \mathrm{O}$ at low temperatures. Both compounds strongly respond to $450 \mathrm{~nm}$ irradiation at $10 \mathrm{~K}$ with a 13 -fold increase of magnetization in the case of $\mathbf{1 M n}$ and a 16-fold increase for $\mathbf{1 M n} \cdot \mathbf{8 H _ { 2 }} \mathrm{O}$ (Figure S26). After $450 \mathrm{~nm}$ irradiation, $\mathbf{1 M n}$ shows clear bifurcation of ZFC-FC curves at $T_{\mathrm{c}}=72 \mathrm{~K}$ (Figure 6), which is slightly lower than for its octacyanotungstate(IV) ana$\log$ with $T_{\mathrm{c}}=93 \mathrm{~K}^{47}$. This behavior is assumed to originate from the photo-induced formation of $S=1 \mathrm{Mo}^{\mathrm{IV}} 103$ which couples magnetically with $S=5 / 2 \mathrm{Mn}^{\mathrm{II}}$ centers and enables ferrimagnetic ordering of the network. ${ }^{102}$ More importantly, photo-induced magnetic ordering at $T_{\mathrm{c}}=40 \mathrm{~K}$ is also demonstrated by the $\mathbf{1 M n} \cdot 8 \mathrm{H}_{2} \mathrm{O}$ in contrast to the lack of the photomagnetic response in the case of its $\left[\mathrm{W}^{\mathrm{IV}}(\mathrm{CN})_{8}\right]$-based analog $\left\{\left[\mathrm{Mn}^{\mathrm{II}}(\mathrm{imH})\left(\mathrm{H}_{2} \mathrm{O}\right)_{2}\right]_{2}\left[\mathrm{~W}^{\mathrm{IV}}(\mathrm{CN})_{8}\right] \cdot 4 \mathrm{H}_{2} \mathrm{O}\right\}_{\mathrm{n} \cdot}{ }^{47}$ However, the photomagnetic behavior of both compounds $1 \mathrm{Mn}$ and $\mathbf{1 M n} \cdot \mathbf{8 H _ { 2 } \mathrm { O }}$ shows signs of irradiation damage, the latter preserving longrange magnetic ordering even after 2 hours of thermal relaxation at $240 \mathrm{~K}$ (Figure S27). As far as we know, 1Mn and $\left\{\left[\mathrm{Mn}^{\mathrm{II}}(\mathrm{imH})\right]_{2}\left[\mathrm{~W}^{\mathrm{IV}}(\mathrm{CN})_{8}\right]\right\}_{\mathrm{n}}$ constitute the first examples of isostructural octacyanometalate(IV)-based photomagnets in which both $\mathrm{Mo}^{\mathrm{IV}}$ and $\mathrm{W}^{\mathrm{IV}}$ congeners demonstrate photo-induced magnetic ordering. ${ }^{41}$ This enables comparison of their photomagnetic functionalities, with the former responding to light even in the case of the fully hydrated network and the latter demonstrating higher magnetic ordering temperature and better reversibility of the photomagnetic effect. 


\section{Conclusions}

A completely nonporous cyanide-bridged coordination polymer $\left\{[\mathrm{Mn}(\mathrm{imH})]_{2}\left[\mathrm{Mo}(\mathrm{CN})_{8}\right]\right\}_{\mathrm{n}}$ with exceptional water sorption, stability, and cyclability is demonstrated. The compound shows outstanding breathing effect with a $34 \%$ volume increase as a result of $>25 \% \mathrm{w} / \mathrm{w}$ water uptake. The breathing of the framework is accompanied/caused by a reversible breaking/formation of an additional Mn- $\mathrm{N}$ coordination bond between $\mathrm{Mn}^{\mathrm{II}}$ centers and $\mathrm{CN}^{-}$ligands. This behavior occurs in three well-defined steps and is completely reversible over tens of water vapor pressure- or temperature-swing cycles with full retention of the water sorption capacity and crystallinity of the compound. It clearly shows that cyanide-bridged coordination polymers demonstrate competitive sorption properties as some of the best MOFs, and the alleged instability of their CN-bridged coordination skeleton is merely a belief rather than a proven fact. Simultaneous changes in the network topology and metal center geometry in the presented compound can be tracked in real time using EPR spectroscopy and significantly affect both magnetic and photomagnetic properties of the material.

The presented results pave the way towards a new generation of cyanide-bridged sorbents that can challenge current state-ofthe-art MOFs and even surpass them as multifunctional molecular materials. Such CN-CPs will combine exceptional sorption properties with various magnetic functionalities like photo-induced magnetization changes or long range magnetic ordering affected by guest molecules. Conversely, these effects can be directly employed to study/monitor guest-exchange phenomena in such sorbents enabling the construction of future gas sensors with unmatched sensitivity.

\section{Experimental section}

Synthesis details. All reagents were used as supplied from commercial sources (Alfa-Aesar). Potassium octacyanomolybdate(IV) was obtained according to the previously reported procedure. ${ }^{104}$

$\left\{\left[\mathrm{Mn}^{I I}(\mathrm{imH})\left(\mathrm{H}_{2} \mathrm{O}\right)_{2}\right]_{2}\left[\mathrm{Mo}^{I V}(\mathrm{CN})_{8}\right] \cdot 4 \mathrm{H}_{2} \mathrm{O}\right\}_{n}\left(\mathbf{1 M n} \cdot \mathbf{8 H} \mathbf{H}_{2} \mathrm{O}\right)$. In order to prevent co-precipitation of $\mathrm{MnO}_{2}$, the synthesis was performed in an oxygen-free glovebox with the use of water deoxygenated by $12 \mathrm{~h}$ reflux under argon atmosphere. A solution containing $0.5 \mathrm{mmol}(100 \mathrm{mg})$ of $\mathrm{MnCl}_{2} \cdot 4 \mathrm{H}_{2} \mathrm{O}$ and $1.0 \mathrm{mmol}$ $(68 \mathrm{mg})$ of imidazole in $10 \mathrm{~mL}$ of water was mixed with a water solution of $0.1 \mathrm{mmol}(50 \mathrm{mg})$ of potassium octacyanomolybdate(IV) dihydrate in $10 \mathrm{~mL}$ of water. After $48 \mathrm{~h}$ yellow column crystals were collected by decantation and dried in air (typical yield: ca. $30 \mathrm{mg}, 40 \%$ ). The purity was confirmed by elemental analysis and PXRD. Anal. calcd for $\mathrm{C}_{14} \mathrm{H}_{24} \mathrm{Mn}_{2} \mathrm{~N}_{12} \mathrm{O}_{8} \mathrm{Mo}$ : C 24.20, H 3.48, N 24.22; found: C 24.43, H 3.16, N 24.29.

$\left\{\left[\mathrm{Mn}^{\mathrm{II}}(\mathrm{imH})\left(\mathrm{H}_{2} \mathrm{O}\right)_{2}\right]\left[\mathrm{Mn}^{I I}(\mathrm{imH})\left(\mathrm{H}_{2} \mathrm{O}\right)\right]\left[\mathrm{Mo}^{\mathrm{IV}}(\mathrm{CN})_{8}\right]\right\}_{n}$ $\left(\mathbf{1 M n} \cdot \mathbf{3} \mathrm{H}_{2} \mathrm{O}\right)$. Hand-milled crystals of $\mathbf{1} \mathbf{M n} \cdot \mathbf{8} \mathrm{H}_{2} \mathrm{O}$ were kept for 12 hours in the desiccator above saturated water solution of lithium chloride at $298 \mathrm{~K}(\mathrm{RH}=11.3 \pm 0.3 \%)^{105}$.

$\left\{\left[\mathrm{Mn}^{I I}(\mathrm{imH})\left(\mathrm{H}_{2} \mathrm{O}\right)\right]_{2}\left[\mathrm{Mo}^{I V}(\mathrm{CN})_{8}\right]\right\}_{n}\left(\mathbf{1 M n} \cdot \mathbf{2} \mathbf{H}_{2} \mathrm{O}\right)$. Hand-milled crystals of $\mathbf{1} \mathbf{M n} \cdot \mathbf{8 H}_{2} \mathrm{O}$ were kept for 12 hours in the desiccator above saturated water solution of potassium hydroxide at $313 \mathrm{~K}$ $(\mathrm{RH}=6.3 \pm 0.4 \%)^{105}$.

$\left\{\left[\mathrm{Mn}^{I I}(\mathrm{imH})\right]_{2}\left[\mathrm{Mo}^{I V}(\mathrm{CN})_{8}\right]\right\}_{n}(\mathbf{1 M n}) . \mathbf{1 M n} \cdot \mathbf{8} \mathbf{H}_{2} \mathrm{O}$ was vacuumdried ( $p \approx 10^{-2}$ mbar) over $\mathrm{P}_{4} \mathrm{O}_{10}$ for 12 hours at room temperature.
$\left\{\left[\mathrm{Cd}^{I I}(\mathrm{imH})\left(\mathrm{H}_{2} \mathrm{O}\right)_{2}\right]_{2}\left[\mathrm{Mo}^{I V}(\mathrm{CN})_{8}\right] \cdot 4 \mathrm{H}_{2} \mathrm{O}\right\}_{n}\left(\mathbf{2} \mathbf{C d} \cdot \mathbf{8} \mathbf{H}_{2} \mathrm{O}\right)$. A solution containing $0.5 \mathrm{mmol}(114 \mathrm{mg})$ of $\mathrm{CdCl}_{2} \cdot 2.5 \mathrm{H}_{2} \mathrm{O}$ and 1.0 mmol $(68 \mathrm{mg})$ of imidazole in $80 \mathrm{~mL}$ of water was mixed with the water solution of $0.1 \mathrm{mmol}(50 \mathrm{mg})$ of potassium octacyanomolybdate(IV) dihydrate in $10 \mathrm{~mL}$ of water. After $24 \mathrm{~h}$ yellow needle crystals were collected by decantation and dried in air (typical yield: ca. $20 \mathrm{mg}, 25 \%$ ). The purity was confirmed by PXRD. Anal. calcd for $\mathrm{C}_{14} \mathrm{H}_{24} \mathrm{Cd}_{2} \mathrm{~N}_{12} \mathrm{O}_{8} \mathrm{Mo}$ : C 20.76, $\mathrm{H} 2.99$, N 20.78; found: C 22.45, H 2.56, N 21.71. The discrepancy between the calculated and observed composition results from solvent loss and concomitant decomposition of the compound after removing crystals from the mother liquor.

$\left\{\left[\mathrm{Mn}^{I I}{ }_{x} \mathrm{Cd}^{I I}{ }_{1-x}(\mathrm{imH})\left(\mathrm{H}_{2} \mathrm{O}\right)_{2}\right]_{2}\left[\mathrm{Mo}^{I V}(\mathrm{CN})_{8}\right] \cdot 4 \mathrm{H}_{2} \mathrm{O}\right\}_{n}$

(2Cd·8H $\left.\mathrm{H}_{2} \mathrm{O}: \mathrm{Mn}\right)$. In order to prevent co-precipitation of $\mathrm{MnO}_{2}$, synthesis was performed in an oxygen-free glovebox with the use of water deoxygenated by $12 \mathrm{~h}$ reflux under argon atmosphere. A solution containing $0.3 \mathrm{mmol}(68 \mathrm{mg})$ of $\mathrm{CdCl}_{2} \cdot 2.5 \mathrm{H}_{2} \mathrm{O}, 0.15 \mathrm{mmol}(30 \mathrm{mg})$ of $\mathrm{MnCl}_{2} \cdot 4 \mathrm{Hs}_{2} \mathrm{O}$ and 1.0 mmol $(68 \mathrm{mg})$ of imidazole in $80 \mathrm{~mL}$ of water was mixed with a water solution of $0.1 \mathrm{mmol}(50 \mathrm{mg})$ of potassium octacyanomolybdate(IV) dihydrate in $10 \mathrm{~mL}$ of water. After $24 \mathrm{~h}$ yellow needle crystals were collected by decantation and dried in air (typical yield: ca. $20 \mathrm{mg}, 25 \%$ ). The purity was confirmed by PXRD. Anal. calcd for $\mathrm{C}_{14} \mathrm{H}_{24} \mathrm{Cd}_{2} \mathrm{~N}_{12} \mathrm{O}_{8} \mathrm{Mo}$ : C 20.76, H 2.99, N 20.78; found: C 23.22, H 2.50, N 22.12. The discrepancy between the calculated and observed composition results from solvent loss and concomitant decomposition of the compound after removing crystals from the mother liquor.

2Cd and 2Cd:Mn were obtained from $\mathbf{2 C d} \cdot \mathbf{8} \mathbf{H}_{2} \mathrm{O}$ and 2Cd$\cdot \mathbf{8} \mathrm{H}_{2} \mathrm{O}$ : $\mathbf{M n}$ respectively, which were vacuum-dried ( $p \approx$ $10^{-2}$ mbar) over $\mathrm{P}_{4} \mathrm{O}_{10}$ for 12 hours at room temperature.

\section{Crystallography.}

Single crystal X-ray diffraction (SCXRD) experiments were performed for $\mathbf{1 M n} \cdot \mathbf{8} \mathbf{H}_{2} \mathrm{O}$ and $\mathbf{2 C d} \cdot \mathbf{8} \mathrm{H}_{2} \mathrm{O}$ using Bruker D8 Quest Eco Photon50 CMOS diffractometer (Mo K $\alpha$ radiation, Triumph ${ }^{\circledR}$ monochromator). Single crystals were moved directly from mother liquor into cryo-oil to avoid solvent loss on air. Absorption corrections, data reduction and unit cell refinements were performed using SADABS and SAINT programs included in the Apex3 suite. The structures were solved using direct methods and refined anisotropically using weighted fullmatrix least-squares on $F^{2}{ }^{106-108}$ Hydrogen atoms of the ligands were placed in calculated positions and refined as riding on the parent atoms. Structural diagrams were prepared using Mercury CSD 4.0. ${ }^{109}$

Powder X-ray diffraction (PXRD) data were obtained at room temperature for ground crystalline samples loaded into glass capillaries $(0.5 \mathrm{~mm}$ in diameter for structural measurements, 0.7 $\mathrm{mm}$ for phase purity measurements). Different hydration states presented in the Figure $1 \mathrm{~b}$ were stabilized in the following conditions: I and VII - saturated water vapor at $298 \mathrm{~K}(\mathrm{RH} \approx 100 \%$, sample in the capillary was always covered with a drop of distilled water to maintain high humidity conditions during the course of the measurement), II - saturated LiCl solution at 298 $\mathrm{K}(\mathrm{RH}=11.3 \pm 0.3 \%), \mathrm{III}-$ saturated $\mathrm{KOH}$ solution at $313 \mathrm{~K}$ $(\mathrm{RH}=6.3 \pm 0.4 \%), \mathrm{IV}-$ dry $\operatorname{argon}$ atmosphere at $298 \mathrm{~K}, \mathrm{~V}-$ saturated $\mathrm{LiCl}$ solution at $298 \mathrm{~K}(\mathrm{RH}=11.3 \pm 0.3 \%)$ and $\mathrm{VI}-$ saturated $\mathrm{CH}_{3} \mathrm{COOK}$ solution at $313 \mathrm{~K}(\mathrm{RH}=18.7 \pm 0.5 \%) .{ }^{105}$ Phase purity measurements were subjected to background correction using the DIFFRAC algorithm implemented in the DIFFRAC.EVA V5 software. The measurements were carried out using Bruker D8 Advance diffractometer $(\mathrm{Cu} \mathrm{K} \alpha$ radiation, 
graphite monochromator). The unit cell parameters of $\mathbf{1 M n}$, $\mathbf{1} \mathbf{M n} \cdot \mathbf{2} \mathrm{H}_{2} \mathrm{O}, \mathbf{1} \mathbf{M n} \cdot \mathbf{3} \mathrm{H}_{2} \mathrm{O}$ were determined using the Winplotr and DICVOL06 indexing software. ${ }^{110,111}$ The obtained parameters were refined by fitting the experimental pattern according to the LeBail method in JANA2006. ${ }^{112}$ The structure determination was performed using a direct-space method FOX software. ${ }^{107}$ The starting models consisted of three molecular fragments: one $\left[\mathrm{Mo}^{\mathrm{IV}}(\mathrm{CN})_{8}\right]^{4-}$ and two $\left[\mathrm{Mn}^{\mathrm{II}}(\mathrm{imH})\right]^{2+}$ (or $\left[\mathrm{Mn}^{\mathrm{II}}(\mathrm{imH})\left(\mathrm{H}_{2} \mathrm{O}\right)\right]^{2+} /\left[\mathrm{Mn}^{\mathrm{II}}(\mathrm{imH})\left(\mathrm{H}_{2} \mathrm{O}\right)_{2}\right]^{2+}$ in the case of $\mathbf{1} \mathbf{M n} \cdot \mathbf{2} \mathbf{H}_{2} \mathrm{O}$ and $\mathbf{1} \mathbf{M n} \cdot \mathbf{3} \mathbf{H}_{2} \mathrm{O}$ ) with bond distances and angles based on the single crystal model of $\mathbf{1 M n} \cdot \mathbf{8} \mathbf{H}_{2} \mathrm{O}$. The obtained preliminary models were, subsequently, refined using the JANA2006 Rietveld software keeping the fragments rigid. The final agreement factors are presented in supplementary materials (Table S2 and S3).

CCDC $2046137\left(\mathbf{1 M n} \cdot \mathbf{8} \mathbf{H}_{\mathbf{2}} \mathbf{O}\right), 2046138\left(\mathbf{2 C d} \cdot \mathbf{8} \mathbf{H}_{\mathbf{2}} \mathbf{O}\right), 2048781$ $\left(\mathbf{1} \mathbf{M n} \cdot \mathbf{3} \mathbf{H}_{2} \mathbf{O}\right), 2048780\left(\mathbf{1} \mathbf{M n} \cdot \mathbf{2 H}_{\mathbf{2}} \mathbf{O}\right)$ and $2048779(\mathbf{1 M n})$ contain the supplementary scXRD crystallographic data for this paper which can be obtained free of charge from the Cambridge Crystallographic Data Centre via www.ccdc.cam.ac.uk/data_request/cif.

Physical characterization. The dynamic vapor sorption measurements were performed using an SMS DVS Resolution apparatus for an initial sample mass of 5-10 mg. Sample mass at each step of water sorption isotherm was assumed stable after reaching the $\mathrm{d} m / \mathrm{d} t<0.002 \% \mathrm{~m}_{0} / \mathrm{min}$ limit. The isosteric enthalpy of water adsorption for each point of adsorption isotherm at $298 \mathrm{~K}$ was calculated by interpolating data obtained at $313 \mathrm{~K}$ to the corresponding data points at $298 \mathrm{~K}$ (Table S1) and then applying the van't Hoff equation:

$$
\Delta H_{a d s}=-R \ln \left(\frac{p_{2}}{p_{1}}\right) \frac{T_{1} T_{2}}{T_{2}-T_{1}}
$$

Average adsorption enthalpy was determined by integrating the obtained curve (Figure S10) within $\Delta m / m_{0}=1.5-25.4 \%$ and then dividing by the range. The QE-TPDA measurements were performed using a homemade thermodesorption apparatus (equipped with a VICI Microvolume TCD-2 thermal conductivity detector, electronic mass flow controllers of the carrier gas Brooks 5850, and a passive room temperature saturator) described in details elsewhere. ${ }^{94-98}$ TGA was performed using a NETZSCH TG 209 F1 Libra under a flow of nitrogen (20 $\mathrm{mL} / \mathrm{min})$. The DSC measurement was performed with the use of a Mettler Toledo DSC 822e. After reaching $200^{\circ} \mathrm{C}$ the measurement of the heating curve was repeated and the second measurement for the anhydrous sample was used as background. Average water adsorption enthalpy from calorimetric measurement was calculated by integrating the DSC curve and dividing the obtained value by the total number of water molecules. Elemental analyses were performed using an ELEMENTAR Vario Micro Cube CHNS analyzer.

EPR spectroscopy. Continuous-wave EPR spectra in X-band were conducted on a Bruker Elexsys E500 spectrometer (Faculty of Chemistry, Jagiellonian University, Kraków, Poland). In situ dehydration-rehydration experiments in X-band were conducted on a Bruker Elexsys E580 spectrometer (Department of Molecular Biophysics, Jagiellonian University, Kraków, Poland). These measurements were performed in a quartz tube shaped like a Pasteur pipette. The narrow side of the tube was closed with a piece of a KIMTECH SCIENCE* Precision Wipe, on which a small amount (ca. $3 \mathrm{mg}$ ) of the sample was placed. Tygon ${ }^{\circledR}$ tubing was used to connect the broad side of the quartz tube with an adapter equipped with a glass stopcock, that was used to deliver purge gas to the sample. In the dehydration experiment, it was connected directly to the source of dry nitrogen gas, while in the rehydration experiment - the nitrogen gas was passed through a water bubbler.

Other spectroscopic measurements. Infrared spectra were recorded using a Nicolet iN10 MX FT-IR microscope in the transmission mode (a small amount of powdered sample was spread on $\mathrm{BaF}_{2}$ pellet). Dehydration-rehydration experiments were performed with the use of a Linkam THMS350V stage. $\mathrm{UV}-\mathrm{V}$ is spectra were measured in transmission mode for samples mixed with paraffin oil between two quartz slides using a PerkinElmer Lambda 35 UV/VIS spectrophotometer equipped with an integrating sphere.

Magnetic and photomagnetic measurements. Magnetic susceptibility measurements were performed using a Quantum Design MPMS-3 Evercool magnetometer in magnetic fields up to 7 T for samples packed into Delrin sample holders. ${ }^{114}$ The experimental data were corrected for the diamagnetism of the sample and the sample holder. Photomagnetic measurements were performed for samples placed between two layers of scotch tape and inserted into the plastic straw. 1Mn was prepared for photomagnetic measurements in the oxygen- and water-free glovebox to prevent its rehydration and $\mathbf{1} \mathbf{M n} \cdot \mathbf{8} \mathrm{H}_{2} \mathrm{O}$ was inserted into the magnetometer and vacuum pumped below 240 $\mathrm{K}$ to avoid its dehydration. Irradiation was performed using 450 $\mathrm{nm}$ light produced by a laser diode (L450P1600MM; power at the sample position $\left.6-10 \mathrm{~mW} / \mathrm{cm}^{2}\right)$.

\section{ASSOCIATED CONTENT}

Supporting Information. "This material is available free of charge via the Internet at http://pubs.acs.org."

\section{AUTHOR INFORMATION}

\section{Corresponding Author}

*Michał Magott - Faculty of Chemistry, Jagiellonian University, 30-387 Kraków, Poland; orcid.org/0000-0002-4566-2636; Email: michal.magott@uj.edu.pl

*Dawid Pinkowicz - Faculty of Chemistry, Jagiellonian University, 30-387 Kraków, Poland; orcid.org/0000-0002-9958-3116; Email: dawid.pinkowicz@uj.edu.pl

\section{Author Contributions}

All authors approved the final version of the manuscript.

\section{ACKNOWLEDGMENT}

This work was financed by the Polish Ministry of Science and Higher Education within the Diamond Grant project (0192/DIA/2017/46) and by the Polish National Science Centre within Sonata Bis $6(2016 / 22 / E / S T 5 / 00055)$ and Opus 15 (2018/29/B/ST4/00328). The authors gratefully acknowledge Prof. Artur Osyczka for providing access to the EPR facility of the Faculty of Biochemistry, Biophysics and Biotechnology, Department of Molecular Biophysics.

\section{REFERENCES}

(1) Furukawa, H.; Cordova, K. E.; O'Keeffe, M.; Yaghi, O. M. The Chemistry and Applications of Metal-Organic Frameworks. Science 2013, 341, 1230444.

(2) Yaghi, O. M.; Kalmutzki, M. J.; Diercks, C. S. Introduction to Reticular Chemistry: Metal-Organic Frameworks and Covalent Organic Frameworks; Wiley-VCH Verlag GmbH \& Co. KGaA, Weinheim, Germany 2019.

(3) Farha, O. K.; Yazaydin, A. Ö.; Eryazici, I.; Malliakas, C. D.; 
Hauser, B. G.; Kanatzidis, M. G.; Nguyen, S. T.; Snurr, R. Q. Hupp, J. T. De Novo Synthesis of a Metal-Organic Framework Material Featuring Ultrahigh Surface Area and Gas Storage Capacities. Nat. Chem. 2010, 2, 944-948.

(4) Kreno, L. E.; Leong, K.; Farha, O. K.; Allendorf, M.; Van Duyne, R. P.; Hupp, J. T. Metal-Organic Framework Materials as Chemical Sensors. Chem. Rev. 2012, 112, 1105-1125.

Yuan, D.; Zhao, D.; Sun, D.; Zhou, H. C. An Isoreticular Series of Metal-Organic Frameworks with Dendritic Hexacarboxylate Ligands and Exceptionally High Gas-Uptake Capacity. Angew. Chem. Int. Ed. 2010, 49, 5357-5361.

Furukawa, H.; Ko, N.; Go, Y. B.; Aratani, N.; Choi, S. B.; Choi, E.; Yazaydin, A. Ö.; Snurr, R. Q.; O’Keeffe, M.; Kim, J.; Yaghi, O. M. Ultrahigh Porosity in Metal-Organic Frameworks. Science 2010, 329, 424-428.

(7) Kosaka, W.; Liu, Z.; Zhang, J.; Sato, Y.; Hori, A.; Matsuda, R.; Kitagawa, S.; Miyasaka, H. Gas-Responsive Porous Magnet Distinguishes the Electron Spin of Molecular Oxygen. Nat. Commun. 2018, 9, 5240.

(8) Canivet, J.; Fateeva, A.; Guo, Y.; Coasne, B.; Farrusseng, D. Water Adsorption in MOFs: Fundamentals and Applications. Chem. Soc. Rev. 2014, 43, 5594-5617.

(9) Furukawa, H.; Gándara, F.; Zhang, Y. B.; Jiang, J.; Queen, W. L.; Hudson, M. R.; Yaghi, O. M. Water Adsorption in Porous MetalOrganic Frameworks and Related Materials. J. Am. Chem. Soc. 2014, 136, 4369-4381.

(10) Bourrelly, S.; Moulin, B.; Rivera, A.; Maurin, G.; DevautourVinot, S.; Serre, C.; Devic, T.; Horcajada, P.; Vimont, A.; Clet, G.; Daturi, M.; Lavalley, J. C.; Loera-Serna, S.; Denoyel, R.; Llewellyn, P. L.; Férey, G. Explanation of the Adsorption of Polar Vapors in the Highly Flexible Metal Organic Framework MIL53(Cr). J. Am. Chem. Soc. 2010, 132, 9488-9498.

(11) Lin, Z.; Zou, R.; Liang, J.; Xia, W.; Xia, D.; Wang, Y.; Lin, J.; Hu, T.; Chen, Q.; Wang, X.; Zhao, Y.; Burrell, A. K. Pore SizeControlled Gases and Alcohols Separation within Ultramicroporous Homochiral Lanthanide-Organic Frameworks. J. Mater. Chem. 2012, 22, 7813-7818.

(12) Shigematsu, A.; Yamada, T.; Kitagawa, H. Selective Separation of Water, Methanol, and Ethanol by a Porous Coordination Polymer Built with a Flexible Tetrahedral Ligand. J. Am. Chem. Soc. 2012, 134, 13145-13147.

(13) Tang, Y.; Dubbeldam, D.; Guo, X.; Rothenberg, G.; Tanase, S. Efficient Separation of Ethanol-Methanol and Ethanol-Water Mixtures Using ZIF-8 Supported on a Hierarchical Porous Mixed-Oxide Substrate. ACS Appl. Mater. Interfaces 2019, 11, 21126-21136

(14) Navarro-Sánchez, J.; Argente-García, A. I.; Moliner-Martínez, Y.; Roca-Sanjuán, D.; Antypov, D.; Campíns-Falcó, P.; Rosseinsky, M. J.; Martí-Gastaldo, C. Peptide Metal-Organic Frameworks for Enantioselective Separation of Chiral Drugs. $J$. Am. Chem. Soc. 2017, 139, 4294-4297.

(15) Hartlieb, K. J.; Holcroft, J. M.; Moghadam, P. Z.; Vermeulen, N. A.; Algaradah, M. M.; Nassar, M. S.; Botros, Y. Y.; Snurr, R. Q.; Stoddart, J. F. CD-MOF: A Versatile Separation Medium. J. Am. Chem. Soc. 2016, 138, 2292-2301.

(16) Deng, H.; Grunder, S.; Cordova, K. E.; Valente, C.; Furukawa H.; Hmadeh, M.; Gándara, F.; Whalley, A. C.; Liu, Z.; Asahina, S.; Kazumori, H.; O’Keeffe, M.; Terasaki, O.; Stoddart, J. F.; Yaghi, O. M. Large-Pore Apertures in a Series of Metal-Organic Frameworks. Science 2012, 336, 1018-1023.

(17) Lykourinou, V.; Chen, Y.; Wang, X. Sen; Meng, L.; Hoang, T.; Ming, L. J.; Musselman, R. L.; Ma, S. Immobilization of MP-11 into a Mesoporous Metal-Organic Framework, MP11@mesoMOF: A New Platform for Enzymatic Catalysis. J. Am. Chem. Soc. 2011, 133, 10382-10385.

(18) Kim, H.; Yang, S.; Rao, S. R.; Narayanan, S.; Kapustin, E. A.; Furukawa, H.; Umans, A. S.; Yaghi, O. M.; Wang, E. N. Water Harvesting from Air with Metal-Organic Frameworks Powered by Natural Sunlight. Science 2017, 356, 430-434.

(19) Kalmutzki, M. J.; Diercks, C. S.; Yaghi, O. M. Metal-Organic Frameworks for Water Harvesting from Air. Adv. Mater. 2018, 30, 1704304.

(20) Rieth, A. J.; Wright, A. M.; Skorupskii, G.; Mancuso, J. L.; Hendon, C. H.; Dincă, M. Record-Setting Sorbents for Reversible Water Uptake by Systematic Anion Exchanges in Metal-Organic
Frameworks. J. Am. Chem. Soc. 2019, 141, 13858-13866.

Hanikel, N.; Prévot, M. S.; Fathieh, F.; Kapustin, E. A.; Lyu, H.; Wang, H.; Diercks, N. J.; Glover, T. G.; Yaghi, O. M. Rapid Cycling and Exceptional Yield in a Metal-Organic Framework Water Harvester. ACS Cent. Sci. 2019, 5, 1699-1706.

Logan, M. W.; Langevin, S.; Xia, Z. Reversible Atmospheric Water Harvesting Using Metal-Organic Frameworks. Sci. Rep. 2020, 10, 1-11.

De Lange, M. F.; Verouden, K. J. F. M.; Vlugt, T. J. H.; Gascon, J.; Kapteijn, F. Adsorption-Driven Heat Pumps: The Potential of Metal-Organic Frameworks. Chem. Rev. 2015, 115, 1220512250 .

Khutia, A.; Rammelberg, H. U.; Schmidt, T.; Henninger, S.; Janiak, C. Water Sorption Cycle Measurements on Functionalized MIL-101Cr for Heat Transformation Application. Chem. Mater. 2013, 25, 790-798.

Rieth, A. J.; Wright, A. M.; Rao, S.; Kim, H.; Lapotin, A. D.; Wang, E. N.; Dinca, M. Tunable Metal-Organic Frameworks Enable High-Efficiency Cascaded Adsorption Heat Pumps. J. Am. Chem. Soc. 2018, 140, 17591-17596.

Côté, A. P.; Benin, A. I.; Ockwig, N. W.; O’Keeffe, M.; Matzger, A. J.; Yaghi, O. M. Chemistry: Porous, Crystalline, Covalent Organic Frameworks. Science 2005, 310, 1166-1170.

Biswal, B. P.; Kandambeth, S.; Chandra, S.; Shinde, D. B.; Bera, S.; Karak, S.; Garai, B.; Kharul, U. K.; Banerjee, R. Pore Surface Engineering in Porous, Chemically Stable Covalent Organic Frameworks for Water Adsorption. J. Mater. Chem. A 2015, 3, 23664-23669.

Jhulki, S.; Evans, A. M.; Hao, X. L.; Cooper, M. W.; Feriante, C. H.; Leisen, J.; Li, H.; Lam, D.; Hersam, M. C.; Barlow, S. Brédas, J. L.; Dichtel, W. R.; Marder, S. R. Humidity Sensing through Reversible Isomerization of a Covalent Organic Framework. J. Am. Chem. Soc. 2020, 142, 783-791.

Nguyen, H. L.; Hanikel, N.; Lyle, S. J.; Zhu, C.; Proserpio, D. M.; Yaghi, O. M. A Porous Covalent Organic Framework with Voided Square Grid Topology for Atmospheric Water Harvesting. J. Am. Chem. Soc. 2020, 142, 2218-2221.

Howarth, A. J.; Liu, Y.; Li, P.; Li, Z.; Wang, T. C.; Hupp, J. T.; Farha, O. K. Chemical, Thermal and Mechanical Stabilities of Metal-Organic Frameworks. Nat. Rev. Mater. 2016, 1, 15018.

Kaye, S. S.; Long, J. R. Hydrogen Storage in the Dehydrated Prussian Blue Analogues $\mathrm{M}_{3}\left[\mathrm{Co}(\mathrm{CN})_{6}\right]_{2}(\mathrm{M}=\mathrm{Mn}, \mathrm{Fe}, \mathrm{Co}, \mathrm{Ni}, \mathrm{Cu}$, Zn). J. Am. Chem. Soc. 2005, 127, 6506-6507.

Chapman, K. W.; Southon, P. D.; Weeks, C. L.; Kepert, C. J. Reversible Hydrogen Gas Uptake in Nanoporous Prussian Blue Analogues. Chem. Commun. 2005, 26, 3322-3324.

Krap, C. P.; Balmaseda, J.; Zamora, B.; Reguera, E. Hydrogen Storage in the Iron Series of Porous Prussian Blue Analogues. Int. J. Hydrog. Energy 2010, 35, 10381-10386.

Krap, C. P.; Balmaseda, J.; Del Castillo, L. F.; Zamora, B.; Reguera, E. Hydrogen Storage in Prussian Blue Analogues: $\mathrm{H}_{2}$ Interaction with the Metal Found at the Cavity Surface. In Energy Fuels 2010, 24, 581-589.

Takahashi, A.; Tanaka, H.; Parajuli, D.; Nakamura, T.; Minami, K.; Sugiyama, Y.; Hakuta, Y.; Ohkoshi, S.; Kawamoto, T. Historical Pigment Exhibiting Ammonia Gas Capture beyond Standard Adsorbents with Adsorption Sites of Two Kinds. J. Am. Chem. Soc. 2016, 138, 6376-6379.

Jiang, Y.; Takahashi, A.; Kawamoto, T.; Asai, M.; Zhang, N.; Lei, Z.; Zhang, Z.; Kojima, K.; Imoto, K.; Nakagawa, K.; Ohkoshi, S.; Nakamura, T. High Performance Sorption and Desorption Behaviours at High Working Temperatures of Ammonia Gas in a Cobalt-Substituted Prussian Blue Analogue. Chem. Commun. 2018, 54, 11961-11964.

Jiang, Y.; Takahashi, A.; Kawamoto, T.; Asai, M.; Zhang, N.; Lei, Z.; Zhang, Z.; Kojima, K.; Nakamura, T. Unique Adsorption and Desorption Behaviour of Ammonia Gas at Heating Temperature Using the Prussian Blue Analogue $\mathrm{Zn}_{3}\left[\mathrm{Co}(\mathrm{CN})_{6}\right]_{2}$. Inorganica Chim. Acta 2020, 501, 119273.

Li, H.; Eddaoudi, M.; O'Keeffe, M.; Yaghi, O. M. Design and Synthesis of an Exceptionally Stable and Highly Porous MetalOrganic Framework. Nature 1999, 402, 276-279.

Burtch, N. C.; Walton, I. M.; Hungerford, J. T.; Morelock, C. R.; Jiao, Y.; Heinen, J.; Chen, Y. S.; Yakovenko, A. A.; Xu, W.; Dubbeldam, D.; Walton, K. S. In Situ Visualization of Loading- 
Dependent Water Effects in a Stable Metal-Organic Framework. Nat. Chem. 2020, 12, 186-192.

(40) Stefańczyk, O.; Ohkoshi, S. Humidity-A Powerful Tool to Customize the Physical Properties of Molecular Magnets. Chem. - A Eur. J. 2019, 25, 15963-15977.

(41) Chorazy, S.; Zakrzewski, J. J.; Magott, M.; Korzeniak, T.; Nowicka, B.; Pinkowicz, D.; Podgajny, R.; Sieklucka, B. Octacyanidometallates for Multifunctional Molecule-Based Materials. Chem. Soc. Rev. 2020, 49, 5945-6001.

(42) Agusti, G.; Ohtani, R.; Yoneda, K.; Gaspar, A. B.; Ohba, M.; Sánchez-Royo, J. F.; Carmen Muñoz, M.; Kitagawa, S.; Real, J. A. Oxidative Addition of Halogens on Open Metal Sites in a Microporous Spin-Crossover Coordination Polymer. Angew. Chem. Int. Ed. 2009, 48, 8944-8947.

(43) Southon, P. D.; Liu, L.; Fellows, E. A.; Price, D. J.; Halder, G. J.; Chapman, K. W.; Moubaraki, B.; Murray, K. S.; Létard, J. F.; Kepert, C. J. Dynamic Interplay between Spin-Crossover and Host-Guest Function in a Nanoporous Metal-Organic Framework Material. J. Am. Chem. Soc. 2009, 131, 10998-11009.

(44) Ohba, M.; Yoneda, K.; Agustí, G.; Muñoz, M. C.; Gaspar, A. B.; Real, J. A.; Yamasaki, M.; Ando, H.; Nakao, Y.; Sakaki, S.; Kitagawa, S. Bidirectional Chemo-Switching of Spin State in a Microporous Framework. Angew. Chem. Int. Ed. 2009, 48, 47674771.

(45) Pinkowicz, D.; Podgajny, R.; Bałanda, M.; Makarewicz, M.; Gaweł, B.; Łasocha, W.; Sieklucka, B. Magnetic Spongelike Behavior of 3D Ferrimagnetic $\left\{\left[\mathrm{Mn}^{\mathrm{II}}(\mathrm{imH})\right]_{2}\left[\mathrm{Nb}^{\mathrm{IV}}(\mathrm{CN})_{8}\right]\right\}_{\mathrm{n}}$ with $T_{\mathrm{c}}=62 \mathrm{~K}$. Inorg. Chem. 2008, 47, 9745-9747.

(46) Pinkowicz, D.; Podgajny, R.; GaweL, B.; Nitek, W.; Łasocha, W.; Oszajca, M.; Czapla, M.; Makarewicz, M.; BaŁanda, M.; Sieklucka, B. Double Switching of a Magnetic Coordination Framework through Intraskeletal Molecular Rearrangement. Angew. Chem. Int. Ed. 2011, 50, 3973-3977.

(47) Magott, M.; Reczyński, M.; Gaweł, B.; Sieklucka, B.; Pinkowicz, D. A Photomagnetic Sponge: High-Temperature Light-Induced Ferrimagnet Controlled by Water Sorption. J. Am. Chem. Soc. 2018, 140, 15876-15882.

(48) Larionova, J.; Chavan, S. A.; Yakhmi, J. V.; Frøystein, A. G.; Sletten, J.; Sourisseau, C.; Kahn, O. Dramatic Modifications of Magnetic Properties through Dehydration-Rehydration Processes of the Molecular Magnetic Sponges $\mathrm{CoCu}(\mathrm{obbz})\left(\mathrm{H}_{2} \mathrm{O}\right)_{4} \cdot 2 \mathrm{H}_{2} \mathrm{O}$ and $\mathrm{CoCu}($ obze $)\left(\mathrm{H}_{2} \mathrm{O}\right)_{4} \cdot 2 \mathrm{H}_{2} \mathrm{O}$, with obbz $=$ N,N'-Bis $(2-$ Carboxyphenyl)Oxamido and obze $=\mathrm{N}-(2-$ Carboxyphenyl $)-\mathrm{N}$ '(Carboxymethyl)Oxamido. Inorg. Chem. 1997, 36, 6374-6381.

(49) Kahn, O.; Larionova, J.; Yakhmi, J. V. Molecular Magnetic Sponges. Chem. - A Eur. J. 1999, 5, 3443-3449.

(50) Loiseau, T.; Serre, C.; Huguenard, C.; Fink, G.; Taulelle, F.; Henry, M.; Bataille, T.; Férey, G. A Rationale for the Large Breathing of the Porous Aluminum Terephthalate (MIL-53) Upon Hydration. Chem. Eur. J. 2004, 10, 1373-1382.

(51) Mellot-Draznieks, C.; Serre, C.; Surblé, S.; Audebrand, N.; Férey, G. Very Large Swelling in Hybrid Frameworks: A Combined Computational and Powder Diffraction Study. J. Am. Chem. Soc. 2005, 127, 16273-16278.

(52) Schneemann, A.; Bon, V.; Schwedler, I.; Senkovska, I.; Kaskel, S.; Fischer, R. A. Flexible Metal-Organic Frameworks. Chem. Soc. Rev. 2014, 43, 6062-6096.

(53) Kosaka, W.; Liu, Z.; Zhang, J.; Sato, Y.; Hori, A.; Matsuda, R.; Kitagawa, S.; Miyasaka, H. Gas-Responsive Porous Magnet Distinguishes the Electron Spin of Molecular Oxygen. Nat. Commun. 2018, 9, 5420.

(54) Chen, J.; Sekine, Y.; Okazawa, A.; Sato, H.; Kosaka, W.; Miyasaka, H. Chameleonic Layered Metal-Organic Frameworks with Variable Charge-Ordered States Triggered by Temperature and Guest Molecules. Chem. Sci. 2020, 11, 3610-3618.

(55) Jeon, I.-R.; Negru, B.; Van Duyne, R. P.; Harris, T. D. A 2D Semiquinone Radical-Containing Microporous Magnet with Solvent-Induced Switching from $T_{\mathrm{c}}=26$ to $80 \mathrm{~K}$. J. Am. Chem. Soc. 2015, 137, 15699-15702.

(56) Liu, L.; Degayner, J. A.; Sun, L.; Zee, D. Z.; Harris, T. D. Reversible Redox Switching of Magnetic Order and Electrical Conductivity in a 2D Manganese Benzoquinoid Framework. Chem. Sci. 2019, 10, 4652-4661.

(57) Qu, L.; Iguchi, H.; Takaishi, S.; Habib, F.; Leong, C. F.; D'alessandro, D. M.; Yoshida, T.; Abe, H.; Nishibori, E.;
Yamashita, M. Porous Molecular Conductor: Electrochemical Fabrication of Through-Space Conduction Pathways among Linear Coordination Polymers. J. Am. Chem. Soc. 2019, 141, 6802-6806.

(58) Coronado, E.; Giménez-Marqués, M.; Espallargas, G. M.; Brammer, L. Tuning the Magneto-Structural Properties of NonPorous Coordination Polymers by $\mathrm{HCl}$ Chemisorption. Nat. Сотmun. 2012, 3, 1-8.

(59) Thorarinsdottir, A. E.; Harris, T. D. Metal-Organic Framework Magnets. Chem. Rev. 2020.

(60) Zhang, J.; Kosaka, W.; Kitagawa, Y.; Miyasaka, H. A MetalOrganic Framework That Exhibits $\mathrm{CO}_{2}$-Induced Transitions between Paramagnetism and Ferrimagnetism. Nat. Chem. 2020, DOI: 10.1038/s41557-020-00577-y.

(61) Sheveleva, A. M.; Kolokolov, D. I.; Gabrienko, A. A.; Stepanov, A. G.; Gromilov, S. A.; Shundrina, I. K.; Sagdeev, R. Z.; Fedin, M. V.; Bagryanskaya, E. G. Structural Dynamics in a "Breathing" Metal-Organic Framework Studied by Electron Paramagnetic Resonance of Nitroxide Spin Probes. J. Phys. Chem. Lett. 2014, 5, 20-24.

(62) Mendt, M.; Gutt, F.; Kavoosi, N.; Bon, V.; Senkovska, I.; Kaskel, S.; Pöppl, A. EPR Insights into Switchable and Rigid Derivatives of the Metal-Organic Framework DUT-8(Ni) by NO Adsorption. J. Phys. Chem. C 2016, 120, 14246-14259.

(63) Han, X.; Godfrey, H. G. W.; Briggs, L.; Davies, A. J.; Cheng, Y.; Daemen, L. L.; Sheveleva, A. M.; Tuna, F.; McInnes, E. J. L.; Sun, J.; Drathen, C.; George, M. W.; Ramirez-Cuesta, A. J.; Thomas, K. M.; Yang, S.; Schröder, M. Reversible Adsorption of Nitrogen Dioxide within a Robust Porous Metal-Organic Framework. Nature Mater. 2018, 17, 691-696.

(64) Li, J.; Han, X.; Zhang, X.; Sheveleva, A. M.; Cheng, Y.; Tuna, F.; McInnes, E. J. L.; McCormick McPherson, L. J.; Teat, S. J.; Daemen, L. L.; Ramirez-Cuesta, A. J.; Schröder, M.; Yang, S. Capture of Nitrogen Dioxide and Conversion to Nitric Acid in a Porous Metal-Organic Framework. Nat. Chem. 2019, 11, 10851090.

(65) Gallagher, A. T.; Malliakas, C. D.; Harris, T. D. CO Binding at a Four-Coordinate Cobaltous Porphyrin Site in a Metal-Organic Framework: Structural, EPR, and Gas Adsorption Analysis. Inorg. Chem. 2017, 56, 4654-4661.

(66) Jiang, Y.; Huang, J.; Kasumaj, B.; Jeschke, G.; Hunger, M.; Mallat, T.; Baiker, A. Adsorption-Desorption Induced Structural Changes of Cu-MOF Evidenced by Solid State NMR and EPR Spectroscopy. J. Am. Chem. Soc. 2009, 131, 2058-2059.

(67) Kultaeva, A.; Bon, V.; Weiss, M. S.; Pöppl, A.; Kaskel, S. Elucidating the Formation and Transformation Mechanisms of the Switchable Metal-Organic Framework ELM-11 by Powder and Single-Crystal EPR Study. Inorg. Chem. 2018, 57, 1192011929.

(68) Poryvaev, A. S.; Sheveleva, A. M.; Demakov, P. A.; Arzumanov, S. S.; Stepanov, A. G.; Dybtsev, D. N.; Fedin, M. V. Pulse EPR Study of Gas Adsorption in Cu2+-Doped Metal-Organic Framework $\left[\mathrm{Zn}_{2}(1,4-\mathrm{bdc})_{2}(\mathrm{dabco})\right]$. Appl. Magn. Reson. 2018, 49, 255-264.

(69) Hunger, M.; Weitkamp, J. In Situ IR, NMR, EPR, and UV/Vis Spectroscopy: Tools for New Insight into the Mechanisms of Heterogeneous Catalysis. Angew. Chem. Int. Ed. 2001, 40, 2954 2971.

(70) Brückner, A. Electron Paramagnetic Resonance: A Powerful Tool for Monitoring Working Catalysts. Adv. Catal. 2007, 51, 265-308.

(71) Sobańska, K.; Pietrzyk, P.; Sojka, Z. Generation of Reactive Oxygen Species via Electroprotic Interaction of $\mathrm{H}_{2} \mathrm{O}_{2}$ with $\mathrm{ZrO}_{2}$ Gel: Ionic Sponge Effect and PH-Switchable Peroxidase- and Catalase-Like Activity. ACS Catal. 2017, 7, 2935-2947.

(72) Pietrzyk, P.; Góra-Marek, K.; Mazur, T.; Mozgawa, B.; Radoń, M.; Chiesa, M.; Zhao, Z.; Sojka, Z. Structure and Mechanistic Relevance of $\mathrm{Ni}^{2+}$-NO Adduct in Model HC SCR Reaction over NiZSM-5 Catalyst - Insights from Standard and Correlation EPR and IR Spectroscopic Studies Corroborated by Molecular Modeling. J. Catal. 2020, DOI: 10.1016/j.jcat.2020.07.018.

(73) Wißmann, G.; Schaate, A.; Lilienthal, S.; Bremer, I.; Schneider, A. M.; Behrens, P. Modulated Synthesis of Zr-Fumarate MOF. Microporous Mesoporous Mater. 2012, 152, 64-70.

(74) Bueken, B.; Reinsch, H.; Reimer, N.; Stassen, I.; Vermoortele, F.; 
Ameloot, R.; Stock, N.; Kirschhock, C. E. A.; De Vos, D. A Zirconium Squarate Metal-Organic Framework with ModulatorDependent Molecular Sieving Properties. Chem. Commun. 2014 50, 10055-10058.

(75) Shen, L.; Zhang, Y.; Uiu, J. Synthesis, Crystal Structure and Magnetic Properties of a Three-Dimensional Cyano-Bridged Heterometallic Complex of Manganese(II) and Molybdenum(IV). J. Coord. Chem. 2006, 59, 629-635.

(76) Wang, Q.-L. L.; Southerland, H.; Li, J.-R. R.; Prosvirin, A. V.; Zhao, H.; Dunbar, K. R. Crystal-to-Crystal Transformation of Magnets Based on Heptacyanomolybdate(III) Involving Dramatic Changes in Coordination Mode and Ordering Temperature. Angew. Chem. Int. Ed. 2012, 51, 9321-9324.

(77) Tanase, S.; Tuna, F.; Guionneau, P.; Maris, T.; Rombaut, G.; Mathonière, C.; Andruh, M.; Kahn, O.; Sutter, J.-P. Substantial Increase of the Ordering Temperature for $\left\{\mathrm{Mn}^{\mathrm{II}} / \mathrm{Mo}^{\mathrm{III}}(\mathrm{CN})_{7}\right\}$ Based Magnets as a Function of the 3d Ion Site Geometry: Example of Two Supramolecular Materials with $T_{\mathrm{c}}=75$ and 106 K. Inorg. Chem. 2003, 42, 1625-1631.

(78) Ohkoshi, S.; Tsunobuchi, Y.; Takahashi, H.; Hozumi, T.; Shiro, M.; Hashimoto, K. Synthesis and Alcohol Vapor Sensitivity of a Ferromagnetic Copper-Tungsten Bimetallic Assembly. J. Am. Chem. Soc. 2007, 129, 3084-3085.

(79) Tsunobuchi, Y.; Hashimoto, K.; Shiro, M.; Hozumi, T.; Ohkoshi, S. Porous Magnets Based on Copper-Octacyanotungsten Containing Noncoordinated Alcohol Molecules. Chem. Lett. 2007, 36, 1464-1465.

(80) Reczyński, M.; Chorazy, S.; Nowicka, B.; Sieklucka, B.; Ohkoshi, S. I. Dehydration of Octacyanido-Bridged $\mathrm{Ni}^{\mathrm{II}}-\mathrm{W}^{\mathrm{IV}}$ Framework toward Negative Thermal Expansion and MagnetoColorimetric Switching. Inorg. Chem. 2017, 56, 179-185.

(81) Imoto, K.; Takahashi, D.; Tsunobuchi, Y.; Kosaka, W.; Arai, M.; Tokoro, H.; Ohkoshi, S. Humidity-Sensitive Magnet Composed of a Cyano-Bridged $\mathrm{Co}^{\mathrm{II}}-\mathrm{Nb}^{\mathrm{IV}}$ Dimetallic Assembly. Eur. J. Inorg. Chem. 2010, 2010, 4079-4082.

(82) Komori-Orisaku, K.; Stefańczyk, O.; Ohishi, S.; Ozaki, N.; Miyamoto, Y.; Imoto, K.; Ohkoshi, S. Humidity-Induced Switching between Two Magnetic and Structural Phases in a $\mathrm{Co}^{\text {II }}$ $\left[\mathrm{W}^{\mathrm{V}}(\mathrm{CN})_{8}\right]$ Molecular Magnet. Chem. - A Eur. J. 2019, 25, 11066-11073.

(83) Nowicka, B.; Rams, M.; Stadnicka, K.; Sieklucka, B. Reversible Guest-Induced Magnetic and Structural Single-Crystal-to-SingleCrystal Transformation in Microporous Coordination Network $\left\{[\mathrm{Ni}(\text { cyclam })]_{3}\left[\mathrm{~W}(\mathrm{CN})_{8}\right]_{2}\right\}_{n}$. Inorg. Chem. 2007, 46, 8123-8125.

(84) Nowicka, B.; Bałanda, M.; Gaweł, B.; Ćwiak, G.; Budziak, A.; Łasocha, W.; Sieklucka, B. Microporous $\left\{[\mathrm{Ni}(\text { cyclam })]_{3}\left[\mathrm{~W}(\mathrm{CN})_{8}\right]_{2}\right\}_{\mathrm{n}}$ Affording Reversible Structural and Magnetic Conversions. Dalton Trans. 2011, 40, 3067-3073.

(85) Chun, H.; Dybtsev, D. N.; Kim, H.; Kim, K. Synthesis, X-Ray Crystal Structures, and Gas Sorption Properties of Pillared Square Grid Nets Based on Paddle-Wheel Motifs: Implications for Hydrogen Storage in Porous Materials. Chem. Eur. J. 2005, 11, 3521-3529.

(86) Roztocki, K.; Formalik, F.; Krawczuk, A.; Senkovska, I.; Kuchta B.; Kaskel, S.; Matoga, D. Collective Breathing in an Eightfold Interpenetrated Metal-Organic Framework: From Mechanistic Understanding towards Threshold Sensing Architectures. Angew. Chem. Int. Ed. 2020, 59, 4491-4497.

(87) Song, B.-Q.; Yang, Q.-Y.; Wang, S.-Q.; Vandichel, M.; Kumar, A.; Crowley, C. M.; Kumar, N.; Deng, C.-H.; GASCON PEREZ, V.; Lusi, M.; Wu, H.; Zhou, W.; Zaworotko, M. J. Reversible Switching between Nonporous and Porous Phases of a New SIFSIX Coordination Network Induced by a Flexible Linker Ligand. J. Am. Chem. Soc. 2020, 142, 6896-6901.

(88) Shigematsu, A.; Yamada, T.; Kitagawa, H. Wide Control of Proton Conductivity in Porous Coordination Polymers. J. Am. Chem. Soc. 2011, 133, 2034-2036.

(89) Coudert, F. X.; Ortiz, A. U.; Haigis, V.; Bousquet, D.; Fuchs, A. H.; Ballandras, A.; Weber, G.; Bezverkhyy, I.; Geoffroy, N.; Bellat, J. P.; Ortiz, G.; Chaplais, G.; Patarin, J.; Boutin, A. Water Adsorption in Flexible Gallium-Based MIL-53 Metal-Organic Framework. J. Phys. Chem. C 2014, 118, 5397-5405.

(90) Devautour-Vinot, S.; Maurin, G.; Henn, F.; Serre, C.; Férey, G. Water and Ethanol Desorption in the Flexible Metal Organic Frameworks, MIL-53 (Cr, Fe), Investigated by Complex
Impedance Spectrocopy and Density Functional Theory Calculations. Phys. Chem. Chem. Phys. 2010, 12, 12478-12485.

(91) Kalmutzki, M. J.; Hanikel, N.; Yaghi, O. M. Secondary Building Units as the Turning Point in the Development of the Reticular Chemistry of MOFs. Sci. Adv. 2018, 4, eaat9180.

(92) Vyazovkin, S.; Burnham, A. K.; Criado, J. M.; Pérez-Maqueda, L. A.; Popescu, C.; Sbirrazzuoli, N. ICTAC Kinetics Committee Recommendations for Performing Kinetic Computations on Thermal Analysis Data. Thermochim. Acta 2011, 520, 1-19.

(93) Blaine, R. L.; Kissinger, H. E. Homer Kissinger and the Kissinger Equation. Thermochim. Acta 2012, 540, 1-6.

(94) Makowski, W. Quasi-Equilibrated Temperature Programmed Desorption and Adsorption: A New Method for Determination of the Isosteric Adsorption Heat. Thermochim. Acta 2007, 454, 2632.

(95) Makowski, W.; Gil, B.; Majda, D. Characterization of Acidity and Porosity of Zeolite Catalysts by the Equilibrated Thermodesorption of N-Hexane and n-Nonane. Catal. Letters 2008, 120, 154-160.

(96) Mańko, M.; Gil, B.; Janus, R.; Kuśtrowski, P.; Makowski, W. Characterization of the Porosity and Surface Chemistry of Mesoporous Silicas by Quasi-Equilibrated Thermodesorption of 1-Butanol and n-Nonane. Thermochim. Acta 2010, 511, 82-88.

(97) Roztocki, K.; Lupa, M.; Sławek, A.; Makowski, W.; Senkovska, I.; Kaskel, S.; Matoga, D. Water-Stable Metal-Organic Framework with Three Hydrogen-Bond Acceptors: Versatile Theoretical and Experimental Insights into Adsorption Ability and Thermo-Hydrolytic Stability. Inorg. Chem. 2018, 57, 32873296.

(98) Sławek, A.; Vicent-Luna, J. M.; Marszałek, B.; Gil, B.; Morris, R. E.; Makowski, W.; Calero, S. Gate-Opening Mechanism of Hydrophilic-Hydrophobic Metal-Organic Frameworks: Molecular Simulations and Quasi-Equilibrated Desorption. Chem. Mater. 2018, 30, 5116-5127.

(99) Jankowski, R.; Reczyński, M.; Chorazy, S.; Zychowicz, M.; Arczyński, M.; Kozieł, M.; Ogorzały, K.; Makowski, W.; Pinkowicz, D.; Sieklucka, B. Guest-Dependent Pressure-Induced Spin Crossover in $\mathrm{Fe}^{\mathrm{II}}{ }_{4}\left[\mathrm{M}^{\mathrm{IV}}(\mathrm{CN})_{8}\right]_{2}(\mathrm{M}=\mathrm{Mo}, \mathrm{W})$ Cluster-Based Material Showing Persistent Solvent-Driven Structural Transformations. Chem. Eur. J. $\mathbf{2 0 2 0}$.

(100) Stoll, S.; Schweiger, A. EasySpin, a Comprehensive Software Package for Spectral Simulation and Analysis in EPR. J. Magn. Reson. 2006, 178, 42-55.

(101) Bridonneau, N.; Long, J.; Cantin, J. L.; Von Bardeleben, J.; Pillet, S.; Bendeif, E. E.; Aravena, D.; Ruiz, E.; Marvaud, V. First Evidence of Light-Induced Spin Transition in Molybdenum(IV). Chem. Commun. 2015, 51, 8229-8232.

(102) Magott, M.; Stefańczyk, O.; Sieklucka, B.; Pinkowicz, D. Octacyanidotungstate(IV) Coordination Chains Demonstrate a Light-Induced Excited Spin State Trapping Behavior and Magnetic Exchange Photoswitching. Angew. Chem. Int. Ed. 2017, 56, 13283-13287.

(103) Qi, X.; Pillet, S.; de Graaf, C.; Magott, M.; Bendeif, E. E.; Guionneau, P.; Rouzières, M.; Marvaud, V.; Stefańczyk, O.; Pinkowicz, D.; Mathonière, C. Photoinduced Mo-CN Bond Breakage in Octacyanomolybdate Leading to Spin Triplet Trapping. Angew. Chem. Int. Ed. 2019, 59, 3117-3121.

(104) Handzlik, G.; Magott, M.; Sieklucka, B.; Pinkowicz, D. Alternative Synthetic Route to Potassium Octacyanidoniobate(IV) and Its Molybdenum Congener. Eur. J. Inorg. Chem. 2016, 2016.

(105) Greenspan, L. Humidity Fixed Points of Binary Saturated Aqueous Solutions. J. Res. Natl. Bur. Stand., Sect A. 1977, 81A, 89-96.

(106) Sheldrick, G. M. A Short History of SHELX. Acta Crystallogr. Sect. A 2008, 64, 112-122.

(107) Sheldrick, G. M. Crystal Structure Refinement with SHELXL. Acta Crystallogr. C. 2015, 71, 3-8.

(108) Dolomanov, O. V; Bourhis, L. J.; Gildea, R. J.; Howard, J. A. K.; Puschmann, H. OLEX2: A Complete Structure Solution, Refinement and Analysis Program. J. Appl. Crystallogr. 2009, 42, 339-341.

(109) MacRae, C. F.; Sovago, I.; Cottrell, S. J.; Galek, P. T. A.; McCabe, P.; Pidcock, E.; Platings, M.; Shields, G. P.; Stevens, J. S.; Towler, M.; Wood, P. A. Mercury 4.0: From Visualization to 
Analysis, Design and Prediction. J. Appl. Crystallogr. 2020, 53, 226-235.

(110) T, R.; J, R.-C. WinPLOTR: A Windows Tool for Powder Diffraction Pattern Analysis. Mater. Sci. Forum 2001, 378-3, 118-123.

(111) Boultif, A.; Louër, D. Powder Pattern Indexing with the Dichotomy Method. J. Appl. Crystallogr. 2004, 37, 724-731.

(112) Petrícek, V.; Dušek, M.; Palatinus, L. Crystallographic Computing System JANA2006: General Features.

Kristallogr. Cryst. Mater. 2014, 229, 345-352.

(113) Favre-Nicolin, V.; Černý, R. FOX, "Free Objects for
Crystallography": A Modular Approach to Ab Initio Structure Determination from Powder Diffraction. J. Appl. Crystallogr. 2002, 35, 734-743

(114) Arczyński, M.; Stanek, J.; Sieklucka, B.; Dunbar, K. R.; Pinkowicz, D. Site-Selective Photoswitching of Two Distinct Magnetic Chromophores in a Propeller-Like Molecule to Achieve Four Different Magnetic States. J. Am. Chem. Soc. 2019 141, 19067-19077.

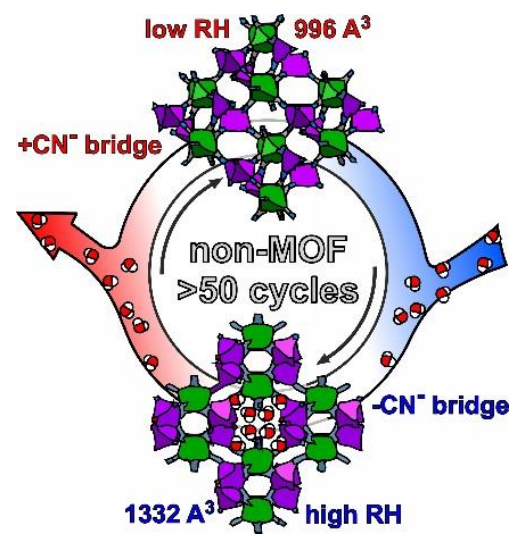

